FY 2005

\title{
EMERGING TWO-PHASE COOLING TECHNOLOGIES FOR POWER ELECTRONIC INVERTERS
}

\section{INTERM REPORT}

Prepared by:

Oak Ridge National Laboratory

Mitch Olszewski, Program Manager

\section{Submitted to:}

Energy Efficiency and Renewable Energy

FreedomCAR and Vehicle Technologies

Vehicle Systems Team

Susan A. Rogers, Technology Development Manager

July 2005 
NATIONAL LABORATORY

MANAGED BY UT-BATTELLE

FOR THE DEPARTMENT OF ENERGY
Engineering Science and Technology Division

\section{EMERGING TWO-PHASE COOLING TECHNOLOGIES FOR POWER ELECTRONIC INVERTERS}

INTERIM REPORT

\author{
J. S. Hsu \\ L. D. Marlino
}

Publication Date: July 2005

Prepared by the

OAK RIDGE NATIONAL LABORATORY

Oak Ridge, Tennessee 37831

managed by

UT-BATTELLE, LLC

for the

U.S. DEPARTMENT OF ENERGY

Under contract DE-AC05-00OR22725 


\section{INTERIM REPORT}

This report was prepared as an account of work sponsored by an agency of the United States Government. Neither the United States Government nor any agency thereof, nor any of their employees, makes any warranty, express or implied, or assumes any legal liability or responsibility for the accuracy, completeness, or usefulness of any information, apparatus, product, or process disclosed, or represents that its use would not infringe privately owned rights. Reference herein to any specific commercial product, process, or service by trade name, trademark, manufacturer, or otherwise, does not necessarily constitute or imply its endorsement, recommendation, or favoring by the United States Government or any agency thereof. The views and opinions of authors expressed herein do not necessarily state or reflect those of the United States Government or any agency thereof. 


\section{INTERIM REPORT}

TABLE CONTENTS

Page

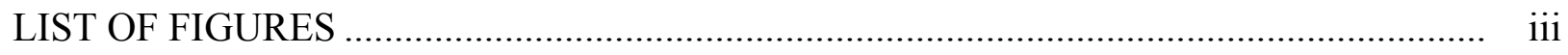

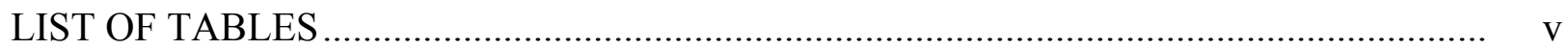

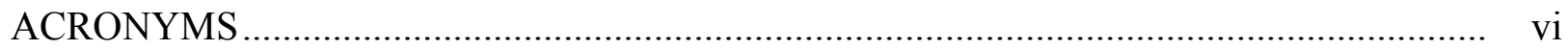

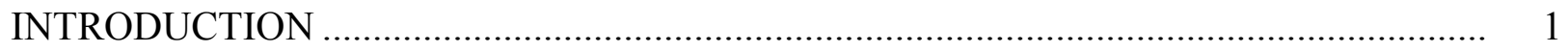

1. ORNL'S ASSESSMENT SUMMARY ON SUBCONTRACTOR'S FINDINGS ............ 2

1.1 ORNL's Assessment on GT/Innovative Fluidics, Single-Loop, Two-Phase

JIC System ……....................................................................................... 3

1.2 ORNL's Assessment on RSC Single-Loop, Two-Phase JIC System ........................ 3

1.3 ORNL's Assessment on ISR Double-Loop, Two-Phase Spray Cooling System...... 4

2. SUBCONTRACTOR'S REPORTS

2.1 GT/INNOVATIVE FLUIDICS REPORTS

2.1.1 Demonstration of a 30/55-kW Inverter Cooled by a VIDA and/or VIBE Two-Phase System...................................................................... 5

2.1.2 Demonstration of a 30/55-kW Inverter Cooled by a VIDA and/or VIBE Two-Phase System ...................................................................... 15

2.2 RSC REPORTS

2.2.1 Jet Impingement Cooling of a 30/55-kW Semikron Inverter Module ............ 20

2.2.2 Demostration of 30/55-kW Semikron Inverter Module Cooled by Jet-Impingement System......................................................................... 22

2.2.3 Demonstration of 30/55-kW Semikron Inverter Module Cooled by Jet Impingement System ........................................................................ 24

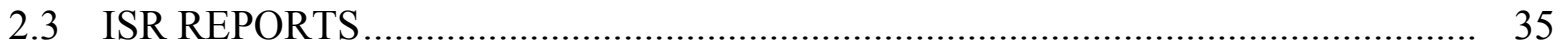

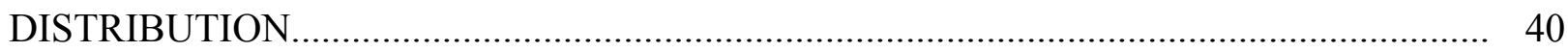




\section{INTERIM REPORT}

\section{LIST OF FIGURES}

\section{Section 2.1.1}

Figure

1 Schematic of VIBE with an ultrasonic actuator....

Page

2 The heat flux dissipated using water with the actuator on ( $\square$ ) and with the actuator off (x)

3 The heat flux dissipated using the WEG mixture with the actuator on ( $\square$ ) and with the actuator off $(\mathrm{x})$.

4 The heat flux dissipated using water and methanol mixture with the actuator on $(\circ)$ and with the actuator off $(\square)$

5 The heat flux dissipated using water with a bulk temperature of $80^{\circ} \mathrm{C}$

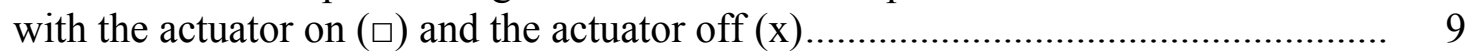

6 Photographs of a modified Semikron heat sink

7 The heat flux dissipated using water with a bulk temperature of $20^{\circ} \mathrm{C}$ with the actuator off, on (1 gpm), and on (2.5 gpm)

8 The heat flux dissipated using water and 50/50 mix of the WEG with a bulk temperature of $85^{\circ} \mathrm{C}$

9 The heat flux dissipated using water with a bulk temperature of $25^{\circ} \mathrm{C}$ with the actuator off, on (1 gpm), and on (3.75 gpm).

10 The heat flux dissipated using water with a bulk temperature of $85^{\circ} \mathrm{C}$ with the actuator on (1 gpm), and on (3.3 gpm)

11 The heat flux dissipated using the WEG mixture with a bulk temperature of $25^{\circ} \mathrm{C}$ with the actuator on and off.....

\section{Section 2.1.2}

Figure

1 Photograph of a modified Semikron heat sink

2 Photograph of Array A - $1.65 \mathrm{MHz}$ actuators

Photograph of Array B - 2.4 MHz actuators

4 Photograph of ORNL experimental set-up.....

7 Photograph of heat-sink corrosion

\section{Section 2.2.1}

Figure

\section{Section 2.2.3}

Figure

1 (a) Exploded view of Semikron's module SKADS4001GD06-145x-W

(b) Layout of 12-IGBT dies and 6-diode dies on the DBC board of each phase leg.

(c) Base plate with pin fins for liquid flow cooling. 


\section{INTERIM REPORT}

\section{LIST OF FIGURES (cont'd)}

\section{Section 2.2.3 (cont'd)}

Figure

2 A schematic of the closed loop liquid micro-jet array impingement cooling system for the Semikron module

3 Base plate modification for targeted micro-jet array impingement underneath each IGBT

$4 \quad$ Closed loop jet impingement cooling setup.................................................... 27

5 Variation of power dissipation $\left(\mathrm{P}_{\mathrm{D}}\right)$ with maximum temperature difference between device junction $\left(\mathrm{T}_{\mathrm{j}, \max }\right)$ and ambient $\left(\mathrm{T}_{\mathrm{amb}}\right)$; average $\mathrm{T}_{\mathrm{amb}}=104.3^{\circ} \mathrm{C}$; flow rate $\mathrm{Q}_{\mathrm{L}}=1.75,2$, and $2.25 \mathrm{gpm}$.

$6 \quad$ IGBT temperature variation $\left(\Delta \mathrm{T}=\mathrm{T}_{\mathrm{j}, \mathrm{max}}-\mathrm{T}_{\mathrm{j}, \min }\right)$ vs. power dissipation $\left(\mathrm{P}_{\mathrm{D}}\right)$ at $\mathrm{Q}_{\mathrm{L}}=1.75$ and $2.25 \mathrm{gpm}$

$7 \quad$ Variation of base plate temperature $\left(T_{b p}\right)$ underneath the phase-I DBC vs. power dissipation $\left(\mathrm{P}_{\mathrm{D}}\right)$ at flow rates $\left(\mathrm{Q}_{\mathrm{L}}\right)=1.75,2$, and $2.25 \mathrm{gpm}$

8 Variation of base plate and average IGBT temperatures among the three phases at flow rate $\mathrm{Q}_{\mathrm{L}}=2.25 \mathrm{gpm}$ 


\section{INTERIM REPORT}

\section{LIST OF TABLES}

\section{Section 2.2.1}

Table

Page

$1 \quad$ Flow rate pressure drop characteristics at various inlet liquid temperatures ............ 21

2 Thermal measurements at $\mathrm{Q}_{\mathrm{L}}=2 \mathrm{gpm}$, corresponding $\Delta \mathrm{P}=19 \mathrm{psi} \ldots \ldots \ldots \ldots \ldots \ldots \ldots \ldots . . . \ldots \ldots$

3 Estimated heat dissipation capability at $\mathrm{T}_{\mathrm{j}, \max }=125^{\circ} \mathrm{C}$ for $2 \mathrm{gpm}$ flow rate .......... 21

\section{Section 2.2.3}

Table

1 Closed loop system pressure drop at different flow rates. Inlet liquid

Page

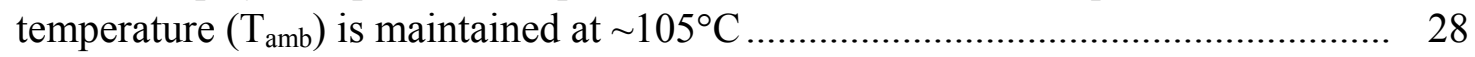




\section{INTERIM REPORT}

\section{ACRONYMS}

ac

AIPM

dc

$\mathrm{CHF}$

COP

DBC

DOE

EETT

FCVT

GT

HEV

IGBT

ISR

JIC

ORNL

RSC

$\mathrm{Si}$

$\mathrm{SiC}$

USCAR

VIBE

VIDA

WEG

\author{
alternating current \\ automotive integrated power \\ module \\ direc current \\ critical heat flux \\ coefficient of performance \\ direct-bonded copper \\ Department of Energy \\ Electrical and Electronics Technical Team \\ FreedomCAR and Vehicle Technologies \\ Georgia Institute of Technology \\ hybrid electric vehicle \\ insulated gate bipolar transistor \\ Isothermal Research Company \\ jet-impingement cooling \\ Oak Ridge National Laboratory \\ Rockwell Scientific Company \\ silicon \\ silicon carbide \\ United States Council for Automotive Research \\ vibration induced bubble ejection \\ vibration induced droplet atomization \\ water-ethylene glycol
}




\section{INTERIM REPORT}

\section{INTRODUCTION}

In order to meet the Department of Energy's (DOE's) FreedomCAR and Vehicle Technologies (FVCT) goals for volume, weight, efficiency, reliability, and cost, the cooling of the power electronic devices, traction motors, and generators is critical.

Currently the power electronic devices, traction motors, and generators in a hybrid electric vehicle (HEV) are primarily cooled by water-ethylene glycol (WEG) mixture. The cooling fluid operates as a single-phase coolant as the liquid phase of the WEG does not change to its vapor phase during the cooling process. In these single-phase systems, two cooling loops of WEG produce a low temperature (around $70^{\circ} \mathrm{C}$ ) cooling loop for the power electronics and motor/generator, and higher temperature loop (around $105^{\circ} \mathrm{C}$ ) for the internal combustion engine.

There is another coolant option currently available in automobiles. It is possible to use the transmission oil as a coolant. The oil temperature exists at approximately $85^{\circ} \mathrm{C}$ which can be utilized to cool the power electronic and electrical devices.

Because heat flux is proportional to the temperature difference between the device's hot surface and the coolant, a device that can tolerate higher temperatures enables the device to be smaller while dissipating the same amount of heat. Presently, new silicon carbide ( $\mathrm{SiC}$ ) devices and high temperature direct current (dc)-link capacitors, such as Teflon capacitors, are available but at significantly higher costs. Higher junction temperature $\left(175^{\circ} \mathrm{C}\right)$ silicon $(\mathrm{Si})$ dies are gradually emerging in the market, which will eventually help to lower hardware costs for cooling.

The development of high-temperature devices is not the only way to reduce device size. Two-phase cooling that utilizes the vaporization of the liquid to dissipate heat is expected to be a very effective cooling method. Among two-phase cooling methods, different technologies such as spray, jet impingement, pool boiling and submersion, etc. are being developed.

The Oak Ridge National Laboratory (ORNL) is leading the research on a novel floating refrigerant loop that cools high-power electronic devices and the motor/generator with very low cooling energy. The loop can be operated independently or attached to the air conditioning system of the vehicle to share the condenser and other mutually needed components. The ability to achieve low cooling energy in the floating loop is attributable to the liquid refrigerant operating at its hot saturated temperature (around $50^{\circ} \mathrm{C}+$ ). In an air conditioning system, the liquid refrigerant is sub-cooled for producing cool air to the passenger compartment. The ORNL floating loop avoids the sub-cooling of the liquid refrigerant and saves significant cooling energy. It can raise the coefficient of performance (COP) more than 10 fold from that of the existing air-conditioning system, where the $\mathrm{COP}$ is the ratio of the cooled power and the input power for dissipating the cooled power.

In order to thoroughly investigate emerging two-phase cooling technologies, ORNL subcontracted three university/companies to look into three leading two-phase cooling technologies. ORNL's assessments on these technologies are summarized in Section I. Detailed descriptions of the reports by the three university/companies (subcontractors) are in Section II. 


\section{INTERIM REPORT}

\section{ORNL'S ASSESSMENT SUMMARY ON SUBCONTRACTORS' FINDINGS}

This report presents the findings of two single-loop, two-phase, WEG cooling systems and a double-loop, two-phase, transmission oil/dielectric fluid system through the tests of prototypes built by three subcontractors. The subcontractors are Georgia Institute of Technology (GT)/Innovative Fluidics, Rockwell Scientific Company (RSC), and Isothermal Research Company (ISR). Because the ISR prototype has not been fully assembled, this report will be updated when ISR completes their work. All three prototype cooling systems were implemented on a modified WEG coolant, single-phase, single-loop Semikron inverter. The $105^{\circ} \mathrm{C}$ WEG coolant was used in GT's vibration induced bubble ejection (VIBE) system as well RSC's jetimpingement cooling (JIC) system for their two-phase, single-loop systems. The $85^{\circ} \mathrm{C}$ transmission oil was used by ISR to cool a second-dielectric fluid loop for direct-die spray cooling. All three subcontractors' systems operate below 30-psi pressure.

The primary issues involved with using a dielectric spray, non-pressurized cooling method for cooling electronics and motors, as presented by the Electrical and Electronics Technical Team (EETT) are:

1. Integrity of exposed wire bonds.

2. Sealing around power terminals, connectors, motor shafts, bearings, etc.

3. Performance integrity with power density of up to $200 \mathrm{~W} / \mathrm{cm}^{2}$.

4. Dielectric fluid cost.

5. Pump cost.

6. Demonstration of $30 \%$ footprint reduction.

7. Release of public domain papers.

8. Serviceability of system.

9. Demonstration of end product cost.

10. Life testing of entire system.

11. Evaluation of coolant fluids.

12. Evaluation of atomizer technology:

a) Producibility of atomizers for mass production,

b) Life test validation of atomizers for a system life of 10 years/150K miles,

c) Sensitivity of atomizer location to components, and

d) Effect of long term atomizer spray to components.

14. Long term cooling performance.

15. Vibration integrity in automotive engine/transmission environment exposed to $17.3 \mathrm{G} \mathrm{rms}$ of random vibration from 10 to $1500 \mathrm{~Hz}$.

16. Sensitivity of cooling performance to variable/unknown heat loading of power devices.

17. Revised pump life test data performed on pumps with all known mechanical enhancements incorporated into the design, performed at using temperature of fluid.

18. Validation of atomizer life-test filtration system and spray-pattern performance at 30 psi.

19. Filtration system maintenance intervals.

20. Economical packaging of power electronics system.

21. Ease of assembly. 


\section{INTERIM REPORT}

22. Evaluation of failure modes with respect to safety.

23. Size of condenser surface area required.

Due to the constraint of time and budget, only the issues surrounding the cooling of $\mathrm{Si}$ dies are addressed in this investigation. In this investigation, the potentials and problems of different two-phase technologies proposed by the three subcontractors can be clearly seen. All test results presented in this report were witnessed by ORNL.

\subsection{ORNL's Assessment on GT/Innovative Fluidics, Single-Loop, Two-Phase JIC System}

The first of the attached reports (see Section II) submitted by GT/ Innovative Fluidics, Demonstration of a 30/55-kW Inverter Cooled by a VIDA and/or VIBE Two-Phase System, Item $\# 00002 \mathrm{~A}$, describes the initial tests using water (without glycol) for the VIBE technology. The cooling results using water were only impressive in a laboratory setting.

The second of the attached reports in Section II, Demonstration of a 30/55-kW Inverter Cooled by a VIDA and/or VIBE Two-Phase System, Item \#00003A, Report \#3 - Final Results, details the failure of the VIBE technology when the $105^{\circ} \mathrm{C}$ WEG was used in the prototype test. It required roughly 760VA (720 VA plus fan motor) of apparent power to cool a $380 \mathrm{~W}$ loss during a de test. Severe erosions were noticed on the surfaces of the piezoelectric vibrators and on the metal-cooling chamber of the inverter after an hour of testing. Very little vaporization occurred due to the high-boiling temperature of the WEG and the low permissible junction temperature $\left(125^{\circ} \mathrm{C}\right)$ of the $\mathrm{Si}$ dies. The WEG boils at $106^{\circ} \mathrm{C}$ at atmosphere pressure. The boiling temperature would increase when the pressure increases.

Although the VIBE technology failed to show its effectiveness from the tests, it may still be worth revisiting when the permissible junction temperature of the dies can be raised to allow more vaporization. However, in order to use this technology, the input power to the piezoelectric vibrators and the cooling fan would have to be reduced and the erosion problem solved.

\subsection{ORNL's Assessment on RSC Single-Loop, Two-Phase JIC System}

The subsequent RSC reports, Status Report - Jet Impingement Cooling of a 30/55KW Semikron Inverter Module, and Final Report - Demonstration of 30/55 KW Semikron Inverter Module Cooled by Jet Impingement System, describe the jet-impingement technique used by RSC with $105^{\circ} \mathrm{C}$ WEG temperature. RSC had developed a closed-loop JIC system. The targeted micro-jet array-impingement technique was implemented on a 450V (dc link voltage) 400A (rms current) Semikron module.

DC testing of the module with $\sim 105^{\circ} \mathrm{C}$ coolant at 2.25 gpm flow rate (corresponding pressure drop $24 \mathrm{psi}$ ) demonstrated 1623 Watts of heat dissipation at an allowable $20^{\circ} \mathrm{C}$ device temperature rise. This translates to a chip-level power dissipation density of $56 \mathrm{~W} / \mathrm{cm}^{2}$, an estimated 1.8X improvement over the state-of-the-art Semikron cold-plate thermal management scheme prorated to the same $105^{\circ} \mathrm{C}$ coolant temperature for comparison. 


\section{INTERIM REPORT}

RSC also estimated that by exposing a portion of the underside of the die directly to the WEG jet by cutting off part of the direct-bonded copper (DBC) underneath the die, the heat flux might potentially reach $90 \mathrm{~W} / \mathrm{cm}^{2}$. There was no extra funding available to perform tests to prove the estimation.

Severe cavitation problems resulting in a pitted impeller was experienced with the WEG pump during the tests.

Tests conducted on the RSC's single-loop, two-phase JIC system indicates that the system has a potential to become a viable cooling method. However, the hardware of the system needs to be improved to overcome cost, size, and reliability issues. The dc bus capacitor cooling issue has not yet been addressed for this cooling system.

\subsection{ORNL's Assessment on ISR Double-Loop, Two-Phase Spray Cooling System}

The attached initial slides of the "ISR SPRAYCOOL SYSTEM" show that the ISR spray cooling method uses an $85^{\circ} \mathrm{C}$ transmission loop to cool a second loop containing the dielectric liquid for spray cooling. The final ISR report and ORNL's assessment will be added upon the completion of the ISR work and the subsequent witnessed testing. 


\title{
2. SUBCONTRACTOR REPORTS
}

\subsection{GT/INNOVATIVE FLUDICS REPORTS}

\subsubsection{Demonstration of a 30/55-kW Inverter Cooled by a VIDA and/or VIBE Two-Phase} System

\author{
Demonstration of a 30/55-kW Inverter Cooled by a VIDA \\ and/or VIBE Two-Phase System \\ Item $\# 00002 \mathrm{~A}$ \\ Report \#2 - Preliminary Testing Results \\ March 27, 2004 - August 20, 2004 \\ Name and business address of subcontractor \\ Samuel Heffington \\ Innovative Fluidics, Inc. \\ 75 5th Street, NW Suite 305 \\ Atlanta, GA 30308 \\ Subcontract number \\ 4000030229 \\ Sponsor \\ John Hsu \\ Oak Ridge National Laboratory \\ National Transportation Research Center \\ 2360 Cherahala Blvd. \\ Knoxville, TN 37932-6472
}

This report covers the period March 27, 2004 to August 20, 2004

Report prepared by:

Sam Heffington

Phone - 404.385.2142

Fax - 404.894.8496

Email - sam.heffington@me.gatech.edu

Work performed during this reporting period:

- A new ultrasonic actuator was evaluated. This actuator operates in the 1.65 to $2.4 \mathrm{MHz}$ range producing no audible noise. The transducers used previously in Report \#1 produced an induced jet but also generated significant acoustic emission (approximately $90 \mathrm{~dB}$ ). 


\section{INTERIM REPORT}

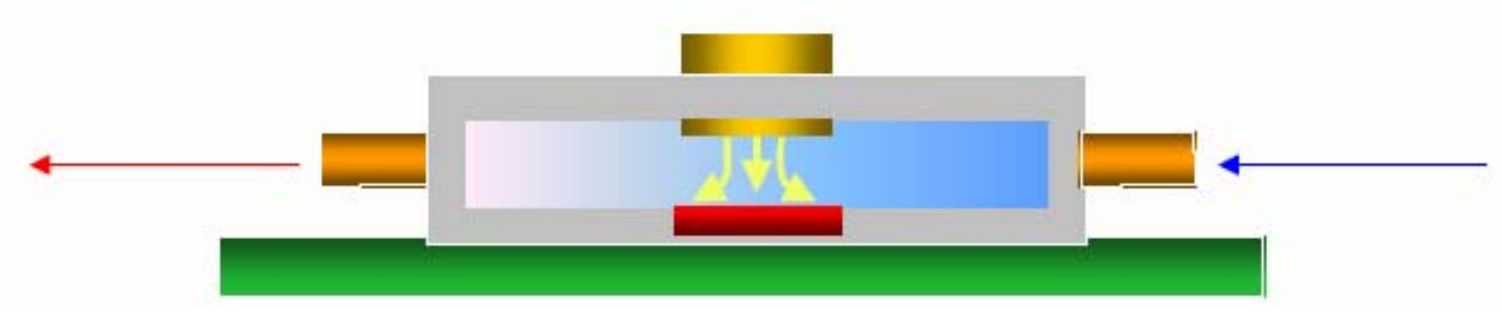

Fig. 1. Schematic of VIBE with an ultrasonic actuator.

- A schematic of one type of VIBE module is shown in Fig. 1. The cell consists of a vibrating driver operating at resonance that generates ultrasonic pressure variations directed at the immersed microelectronic component. As vapor forms on the chip surface, the action of the pressure differences generates instabilities removing the vapor bubbles allowing cooler bulk fluid to wet the hot boiling surface. The ejected vapor bubbles are cooled and condensed by the bulk liquid that is circulated through the cell. The entire cell can be very small, and the driver requires only a few watts of energy to operate.

- In order to test the cooling efficacy of the ultrasonic vibrations, an immersion VIBE heat transfer module was constructed. The experimental set-up was open to the atmosphere, and no effort was made to condense or collect the evaporated liquid. Each experiment was conducted in a small two gallon water tank. The ultrasonic actuator was mounted onto a variable height traverse attached to the bottom of the water tank. A copper calibrated heater was placed in the tank with the $1 \mathrm{~cm}$ by $1 \mathrm{~cm}$ exposed surface facing down. The calibrated copper heater contains several rows of thermocouples located in a one-dimensional conduction region. The output of these imbedded temperature sensors within heater was measured, displayed, and recorded with a data acquisition system. Resistance cartridge elements supplied heat to the calibrated piece of copper. The amount of heat dissipated on the surface of the copper heater as well as the surface temperature was calculated using the thermocouple data. In each of the experiments, the water tank was filled with distilled water submerging the actuator and the surface of the calibrated heater. 


\section{INTERIM REPORT}

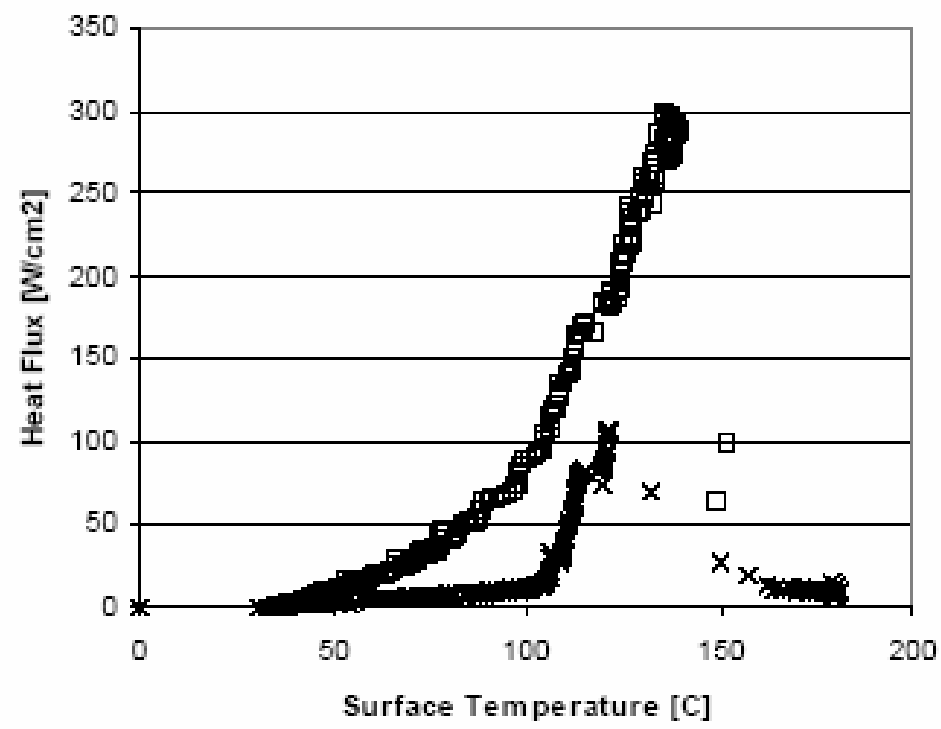

Fig 2. The heat flux dissipated using water with the actuator on ( $\square$ ) and with the actuator off (x).

- In the first experiment, the effect of the actuator directed toward the calibrated heater was measured. Data was obtained for two different scenarios: pool boiling with the actuator on and pool boiling with the actuator off. The results are shown in Fig. 2. Below a heater temperature of $100^{\circ} \mathrm{C}$ (the onset of boiling), the presence of the vibration increased the amount of heat dissipated for a given temperature. The pressure differences provided forced convection heat transfer from the chip to the pool of water. The added turbulent mixing and bulk motion present when the actuator was on compared to the free convection heat transfer when the actuator was off resulted in higher heat fluxes. Above $100^{\circ} \mathrm{C}$, the VIBE effect was present when the actuator was on. By removing the insulating vapor bubbles from the surface of the heater, the heat flux dissipated as a function of heater temperature increased at a faster rate. At a heater temperature of $120^{\circ} \mathrm{C}$, the heat flux dissipated increased from $107 \mathrm{~W} / \mathrm{cm}^{2}$ with the actuator off to $191 \mathrm{~W} / \mathrm{cm}^{2}$ when the actuator was on. This $78 \%$ improvement was a result of the VIBE process increasing the overall heat transfer coefficient through increased convection and the removal of insulating vapor bubbles.

- Figure 3 shows the effect of an actuator directed toward the calibrated heater when the working fluid is a 50/50 mixture of water and ethylene glycol (WEG) (antifreeze). Below a temperature of $130^{\circ} \mathrm{C}$, the presence of the vibrations from the actuator has no effect on the level of heat dissipated. Above $130^{\circ} \mathrm{C}$, the instabilities generated by the vibrating actuator dislodge the vapor bubbles resulting in extended critical heat flux (CHF). With no vibration present, the $\mathrm{CHF}$ was $235 \mathrm{~W} / \mathrm{cm}^{2}$ at a temperature of $157^{\circ} \mathrm{C}$. This $\mathrm{CHF}$ level increased $106 \%$ when the actuator was energized to a level of $485 \mathrm{~W} / \mathrm{cm}^{2}$ at a temperature of $153^{\circ} \mathrm{C}$. 


\section{INTERIM REPORT}

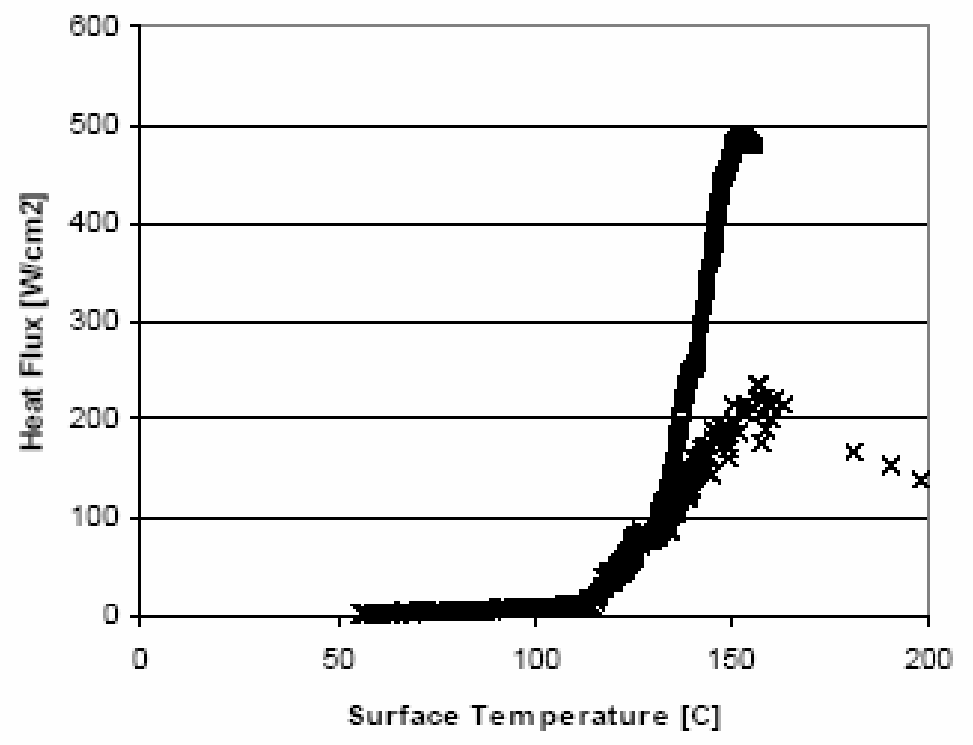

Fig 3. The heat flux dissipated using the WEG mixture with the actuator on ( $\square$ ) and with the actuator off $(x)$.

- The effect of an actuator in a 70/30 mixture of water and methanol is shown in Fig. 4. This nonflammable mixture begins to change phase below $100^{\circ} \mathrm{C}$ providing increased opportunity to take advantage of the phase change boiling enhancements. Below a temperature of $105^{\circ} \mathrm{C}$, the presence of the vibrations from the actuator has no effect on the level of heat dissipated. Above $105^{\circ} \mathrm{C}$, the instabilities generated by the vibrating actuator dislodge the vapor bubbles resulting in an extended $\mathrm{CHF}$. With no vibration present, the CHF was $103 \mathrm{~W} / \mathrm{cm}^{2}$ at a temperature of $103^{\circ} \mathrm{C}$. This $\mathrm{CHF}$ level increased $425 \%$ when the actuator was energized to a level of $655 \mathrm{~W} / \mathrm{cm}^{2}$ at a temperature of $133^{\circ} \mathrm{C}$.

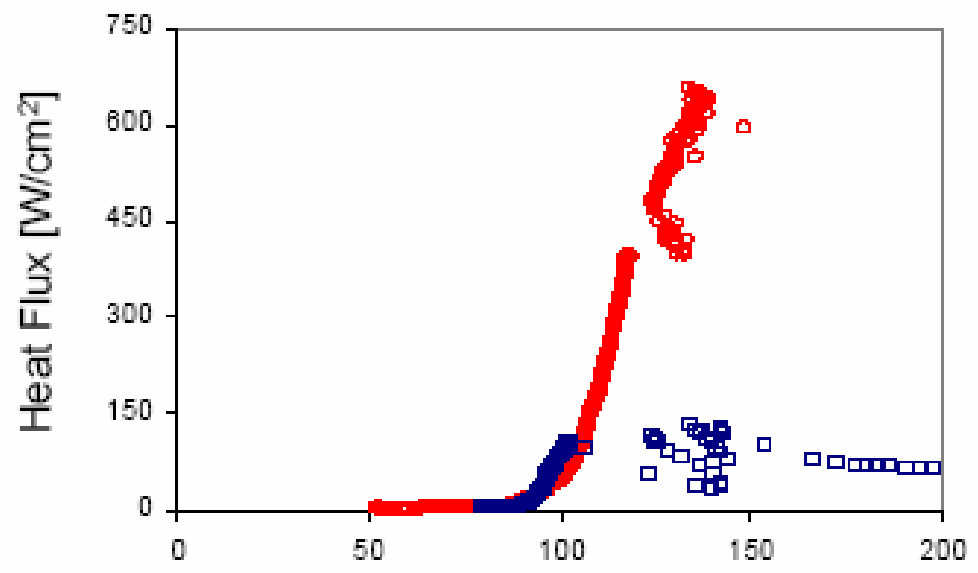

Surface Temperature $\left[{ }^{\circ} \mathrm{C}\right]$

Fig. 4. The heat flux dissipated using water and methanol mixture with the actuator on $(\circ)$ and with the actuator off ( $\square)$. 


\section{INTERIM REPORT}

- Another initial set of experiments examined the effect of the pool bulk temperature with pure water as the working fluid. Figure 5 shows the heat flux from the calibrated heater as a function of the surface temperature for an elevated pool temperature of $80^{\circ} \mathrm{C}$. This data shows that the vibration extended the $\mathrm{CHF}$, but did not improve the heat dissipation at lower temperatures. At temperature of $125^{\circ} \mathrm{C}$, the CHF increased from $127 \mathrm{~W} / \mathrm{cm}^{2}$ to $302 \mathrm{~W} / \mathrm{cm}^{2}$ as the actuator was energized. This ability of the VIBE process to improve the heat dissipation as elevated bulk temperatures provides further design flexibility in the implementation of a VIBE heat transfer module for microelectronic cooling applications.

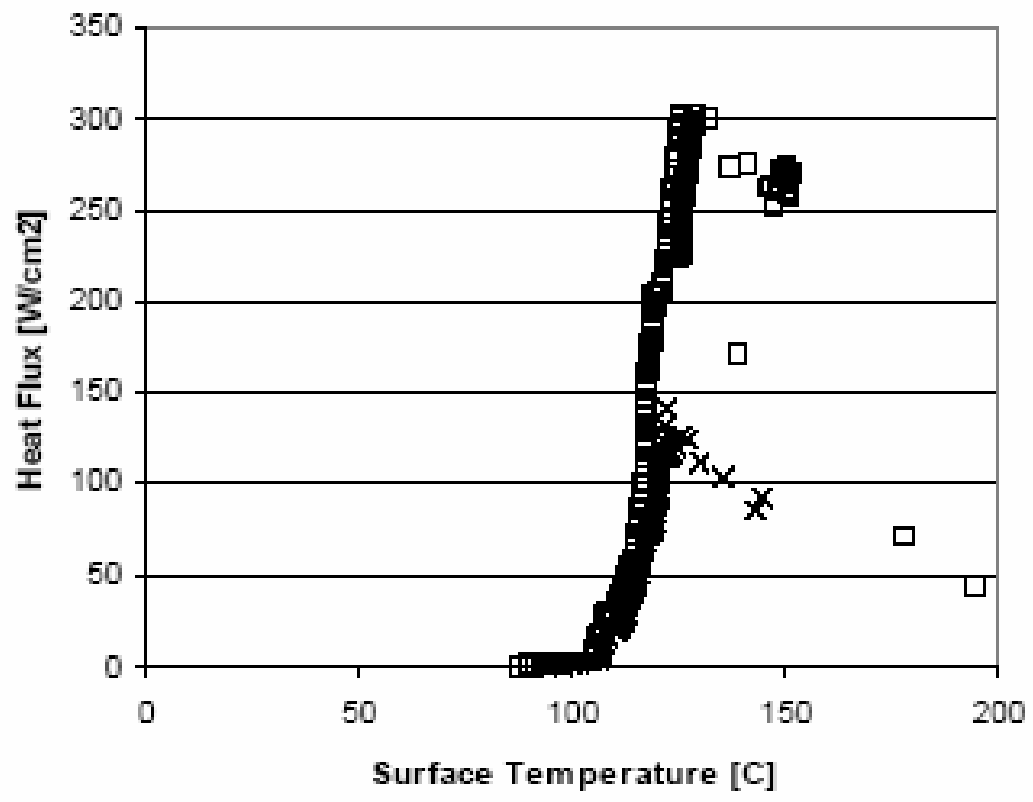

Fig. 5. The heat flux dissipated using water with a bulk temperature of $80^{\circ} \mathrm{C}$ with the actuator on ( $\square)$ and with the actuator off $(x)$.

- A presentation was made at the review meeting held in Knoxville May 2005, discussing the subcontract research and progress. At this meeting the VIBE technology was introduced and the potential based on experimental testing was described.

- Innovative Fluidics received an automotive integrated power module (AIPM) heat sink from Semikron. This heat sink was modified by removing a 2 inch portion of the fins from the middle of the fluid channel. The other fins were left in place to uniformly distribute the flow. As shown in Fig. 6, a single calibrated copper heater was attached to the heat sink such that heat was supplied to the center of the region with no fins. Experimental tests were conducted with both an induced-jet actuator and an ultrasonic actuator. In both cases, a single transducer was aligned directly opposite the calibrated heater. In this experimental set-up, the fluid temperature and the flow rate into the cell were varied and controlled using a chilled water bath. 


\section{INTERIM REPORT}

Top View

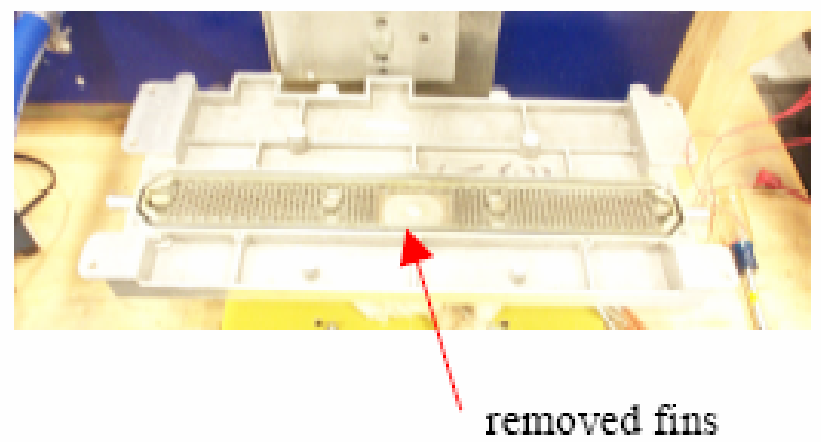

Side View

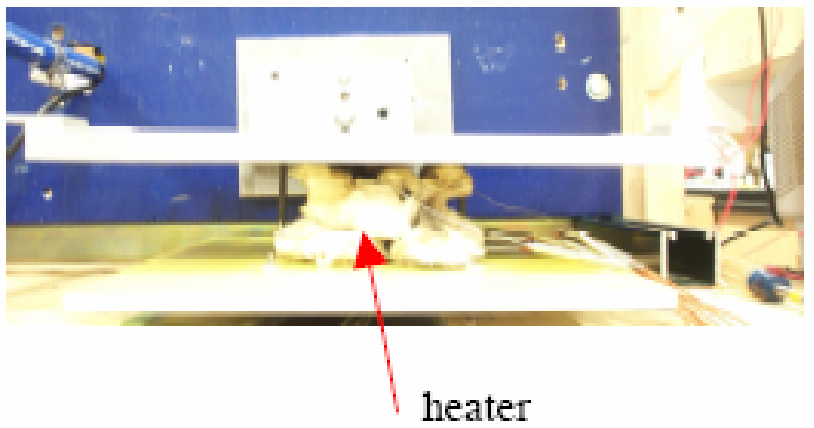

Fig. 6. Photographs of a modified Semikron heat sink.

- Figure 7 presents the heat flux dissipated by the induced cavitation jet for a variety of cross flow rates. The subcooled water temperature was $20^{\circ} \mathrm{C}$, and the actuator was $6 \mathrm{~mm}$ from the heated surface. An improvement in performance exists for low inlet temperature when the jet is energized. The rate of flow does not significantly affect the jet-heat dissipation performance.

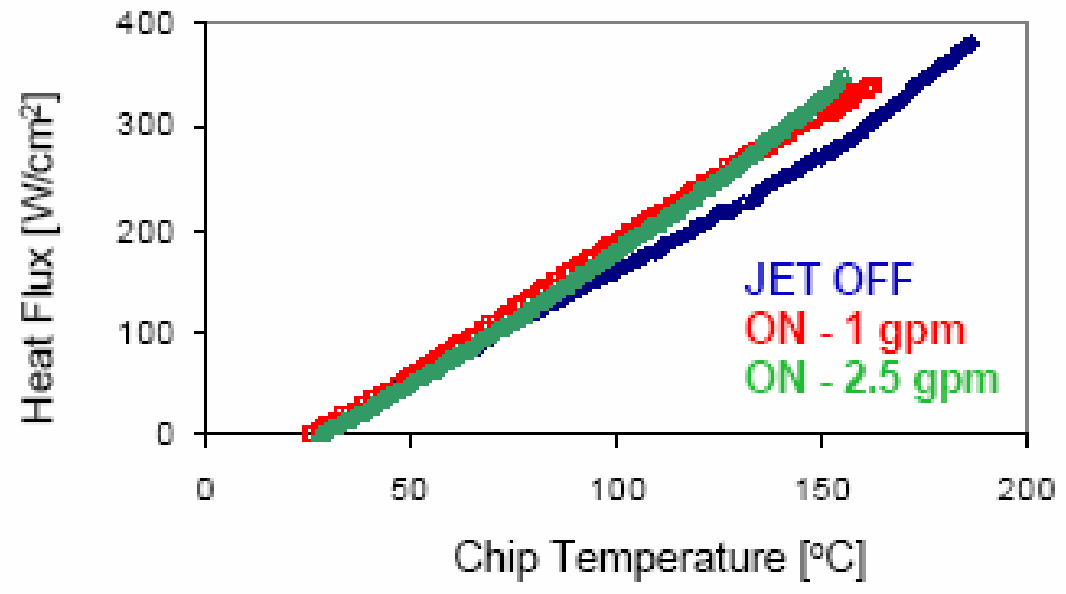

Fig. 7. The heat flux dissipated using water with a bulk temperature of $20^{\circ} \mathrm{C}$ with the actuator off, on (1 gpm), and on (2.5 gpm).

- Figure 8 presents the heat flux dissipated by the induced cavitation jet at elevated inlet temperatures and with a mixture of the WEG. The subcooled water temperature was $85^{\circ} \mathrm{C}$, and the actuator was $6 \mathrm{~mm}$ from the heated surface. The flow rate through the cell was a constant $1.0 \mathrm{gpm}$. For both water and the WEG mixture, the heater dissipated over $100 \mathrm{~W} / \mathrm{cm}^{2}$ at $125^{\circ} \mathrm{C}$, which is above the estimated level required. 


\section{INTERIM REPORT}

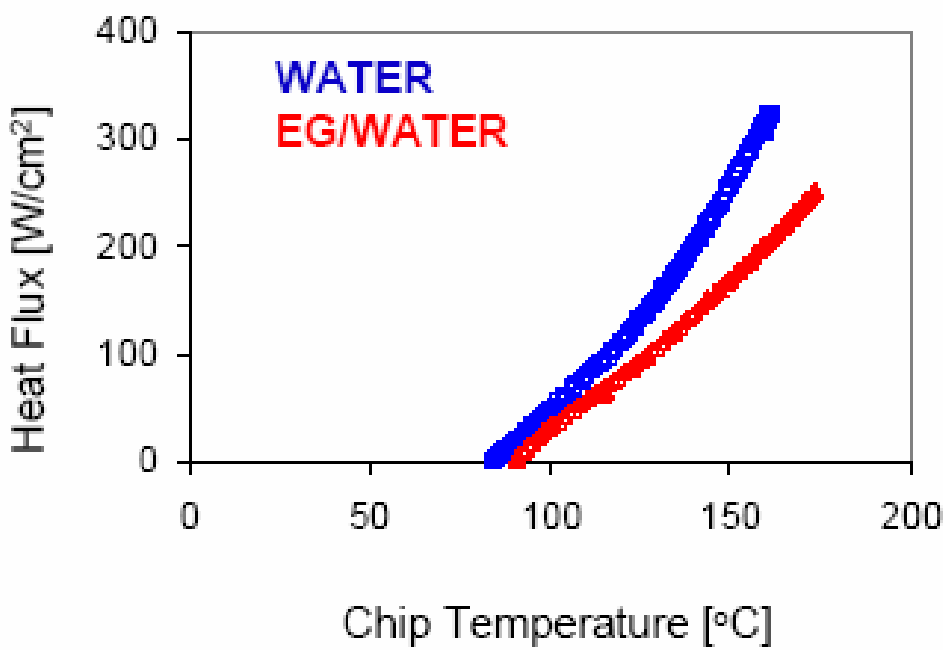

Fig. 8. The heat flux dissipated using water and 50/50 mix of the WEG with a bulk temperature of $85^{\circ} \mathrm{C}$.

- The induced jet Semikron heat transfer cell tests were productive. As the cross flow rate increases, the effect of the jet decreases. The jet did demonstrate heat-transfer dissipation improvement as elevated inlet temperatures. This prototype dissipated over $100 \mathrm{~W} / \mathrm{cm}^{2}$ at $125^{\circ} \mathrm{C}$. Based on the reaction from the auto maker representatives at the United States Council for Automotive Research (USCAR) to the acoustic emission levels associated with the induced jet, Innovative Fluidics has decided to use the ultrasonic actuators for the final AIPM prototype and testing.

- The induced-jet actuator was replaced with an ultrasonic actuator for the same Semikron prototype heat sink shown in Fig. 6. This driver aligned with the copper calibrated heater improved heat dissipation by producing pressure variation near the heated surface. The vibrations from the actuator force movement in the contact line between the vapor and liquid on the hot surface. This contact line motion results in ejection of the vapor bubbles into the bulk liquid flow. By preventing an insulting blanket of vapor from forming on the hot surface, the ultrasonic VIBE process results in improved heat flux at lower device temperatures.

- Figure 9 presents the heat flux dissipated by the ultrasonic actuator for a variety of cross flow rates. The subcooled water temperature was $25^{\circ} \mathrm{C}$, and the actuator was $12 \mathrm{~mm}$ from the heated surface. An improvement in performance exists for low inlet temperature when contact line vibration is present. The rate of flow does not affect the ultrasonic actuator performance. 


\section{INTERIM REPORT}

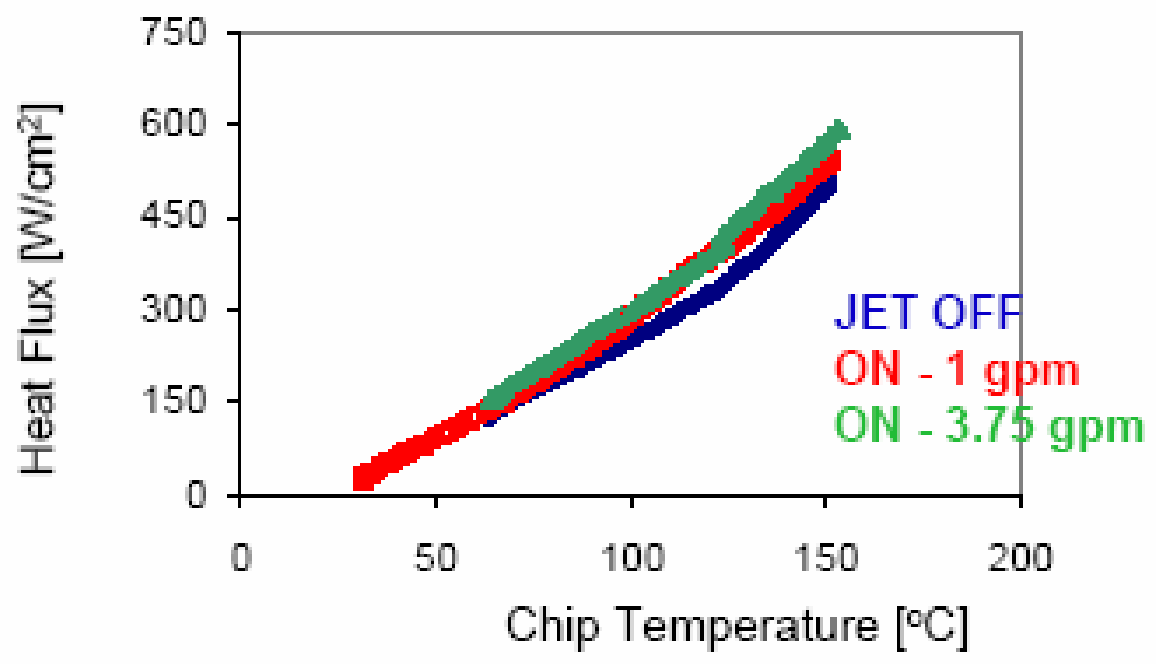

Fig. 9. The heat flux dissipated using water with a bulk temperature of $25^{\circ} \mathrm{C}$ with the actuator off, on (1 gpm), and on (3.75 gpm).

- Figure 10 presents the heat flux dissipated by the ultrasonic actuator at elevated inlet temperatures. The subcooled water temperature was $85^{\circ} \mathrm{C}$, and the actuator was $12 \mathrm{~mm}$ from the heated surface. The flow rate through the cell was changed from $1.0 \mathrm{gpm}$ to $3.3 \mathrm{gpm}$. For both of these flow rates, the presence of vibration resulted in a $30 \%$ improvement in heat dissipation. To extend the level of improvement above $30 \%$, the actuators need to be closer to the heated surface. The pressure differences that generate the vapor bubble ejection decrease with increased separation distance. The acoustic energy produced by the actuator is dissipated in the fluid as the pressure wave travels through the fluid. The smaller separation distance should produce larger pressure differences due to less acoustic energy dissipation.

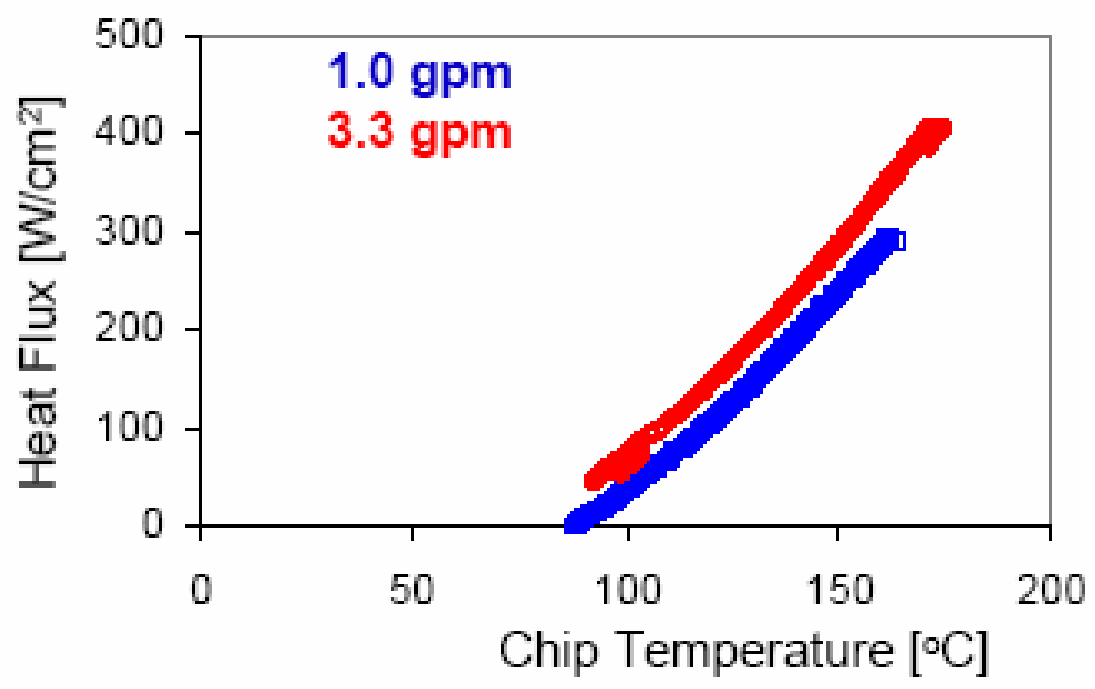

Fig. 10. The heat flux dissipated using water with a bulk temperature of $85^{\circ} \mathrm{C}$ with the actuator on $(1 \mathrm{gpm})$, and on $(3.3 \mathrm{gpm})$. 


\section{INTERIM REPORT}

- Figure 11 presents the effect of working fluid on the heat flux dissipated by the ultrasonic actuator. The subcooled water temperature was $25^{\circ} \mathrm{C}$, and the actuator was $12 \mathrm{~mm}$ from the heated surface. The flow rate through the cell was a constant $0.5 \mathrm{gpm}$. There is a slight improvement in dissipation when the actuator is energized for the 50/50 mixture of WEG. The corrosive nature of the mixture interferes with the ability of the actuator to generate the maximum level of vibration.

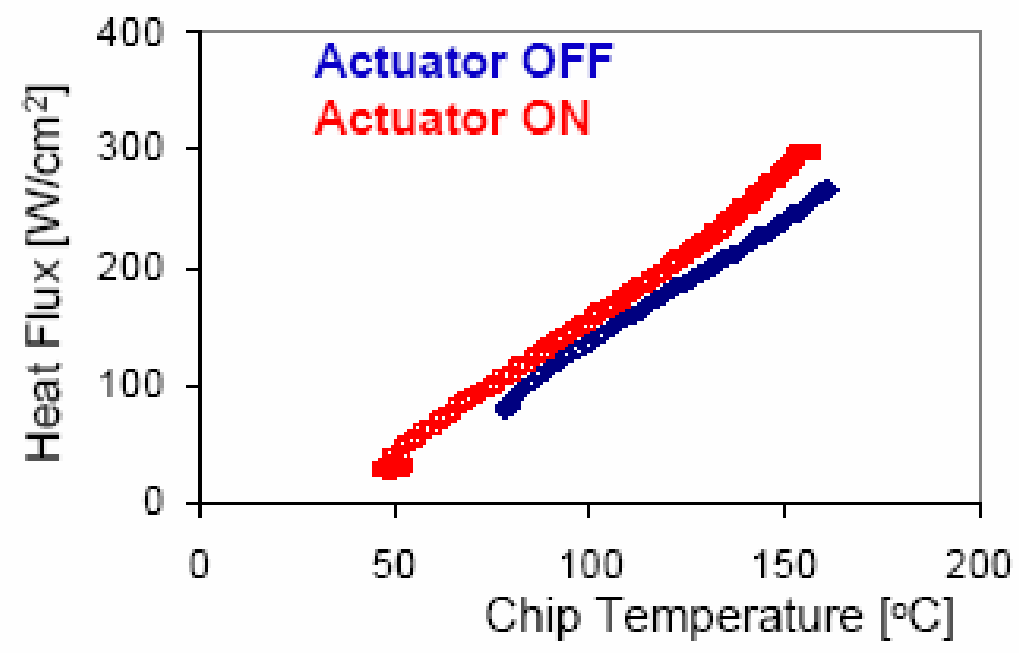

Fig. 11. The heat flux dissipated using the WEG mixture with a bulk temperature of $25^{\circ} \mathrm{C}$ with the actuator on and off.

- The ultrasonic VIBE Semikron heat-transfer cell tests were also productive. The rate of cross flow does not affect the performance of the ultrasonic driver. The jet did demonstrate heat-transfer dissipation improvement as elevated inlet temperatures. The maximum increase in dissipate of $30 \%$ occurred for the $25^{\circ} \mathrm{C}$ inlet temperature case. This prototype dissipated over $100 \mathrm{~W} / \mathrm{cm}^{2}$ at $125^{\circ} \mathrm{C}$.

- It was agreed that Innovative Fluidics personnel could observe the de testing at ORNL. This will save considerable time.

- Innovative Fluidics removed more fins from the AIPM heat sink. The modified heat sink was returned to Semikron for electronic build-up and instrumentation.

\section{Work to be performed during the next reporting period:}

- Innovative Fluidics will construct an array of 30 ultrasonic actuators (10 per leg) to cool the entire AIPM module. In addition to the actuator array, Innovative Fluidics will assemble the necessary electronic circuitry to drive the actuators. The initial dc testing will be conducted at ORNL. These tests will determine the effect of the actuators, the effect of the separation distance between the actuator array and the hot surface, and the effect of the cross flow rate. It is anticipated that all 30 actuators may not be needed to produce the heat-dissipation performance required. 


\section{INTERIM REPORT}

- Upon completion of the de test, Innovative Fluidics will modify the actuator array if necessary and delivery a final prototype to ORNL for further testing and demonstration. This prototype, along with a final report outlining the dc test results, will comprise the final milestone completing Phase I of the project. 


\title{
2.1.2 Demonstration of a 30/55-kW Inverter Cooled by a VIDA and/or VIBE Two-Phase System
}

\author{
Demonstration of a 30/55-kW Inverter Cooled by a VIDA \\ and/or VIBE Two-Phase System \\ Item $\# 00003 \mathrm{~A}$ \\ Report \#3 - Final Results \\ August 21, 2004 - October 5, 2004 \\ Name and business address of subcontractor \\ Samuel Heffington \\ Innovative Fluidics, Inc. \\ 75 5th Street, NW Suite 305 \\ Atlanta, GA 30308 \\ Subcontract number \\ 4000030229 \\ Sponsor \\ John Hsu \\ Oak Ridge National Laboratory \\ National Transportation Research Center \\ 2360 Cherahala Blvd. \\ Knoxville, TN 37932-6472 \\ This report covers the period August 21, 2004 to October 5, 2004 \\ Report prepared by: \\ Sam Heffington \\ Phone - 404.385.2142 \\ Fax - 404.894.8496 \\ Email - sam.heffington@me.gatech.edu
}

\section{Work performed during this reporting period:}

- Following the investigations of the single VIBE ultrasonic actuator detailed in Report \#2, an array of actuators was designed in order to cool the entire Semikron AIPM module. This array design consists of 26 individual actuators spaced evenly across the heat producing area of the AIPM heat sink.

- The modified heat sink with instrumented thermocouples was received from Semikron. The majority of the fins were removed to enable the pressure waves generated by the ultrasonic drivers to interact effectively with the boiling bubbles produced on the surface of the heat sink. Figure 1 is a photograph of the modified Semikron heat sink. This photograph shows three rows of fins at the exit and entrance of the channel used to straighten the flow ensuring laminar conditions. The o-ring shown was added in order to seal the heat sink and actuator array. 


\section{INTERIM REPORT}

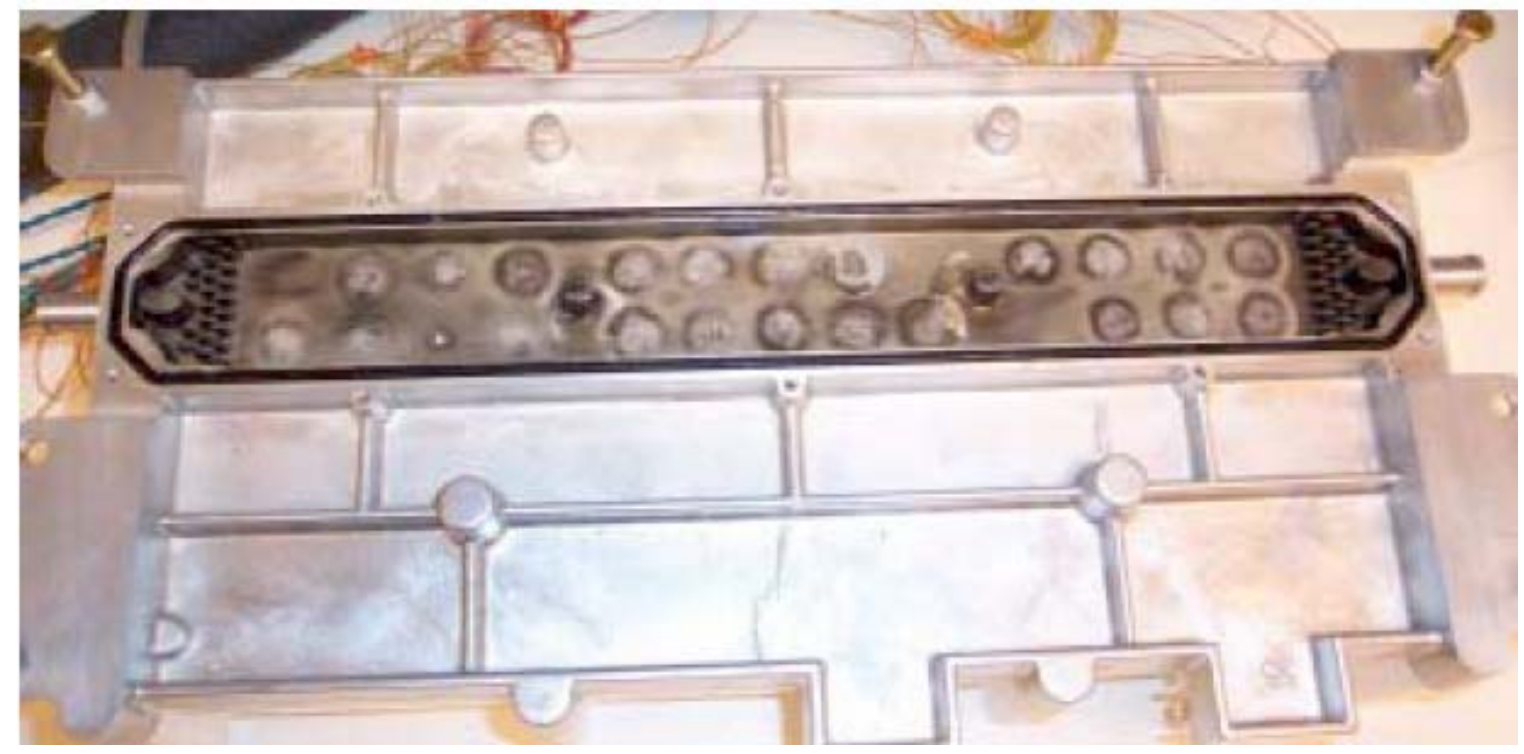

Fig. 1. Photograph of a modified Semikron heat sink.

- While Semikron was building the AIPM module on our modified heat sink, two separate arrays of actuators were constructed. The only difference between the two arrays was the type of ultrasonic actuator used. In Array A, $1.65 \mathrm{MHz}$ actuators were installed, while Array B contained $2.4 \mathrm{MHz}$ transducers. Both types of actuator have the same outer diameter and oscillate in the same manner just at different resonant frequencies. In order to drive the arrays, a separate electronic box containing the amplification and signal generation electronics was constructed. Photographs of each array along with the appropriate electronic box are shown in Figs. 2 and 3.

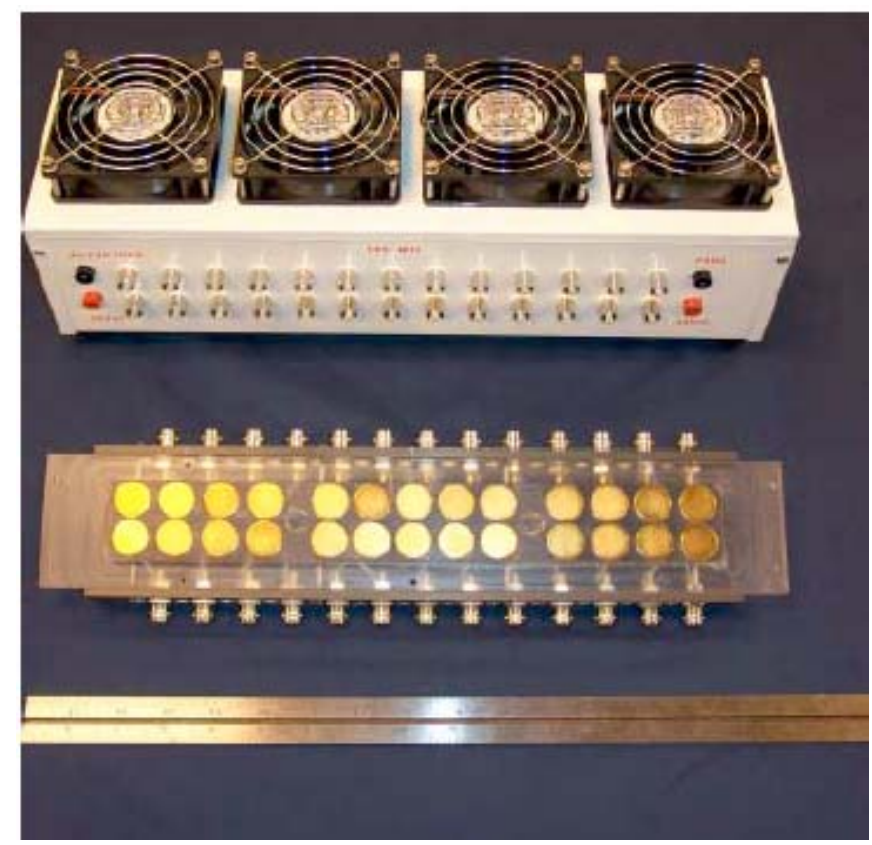

Fig. 2. Photograph of Array A - 1.65 MHz actuators. 


\section{INTERIM REPORT}

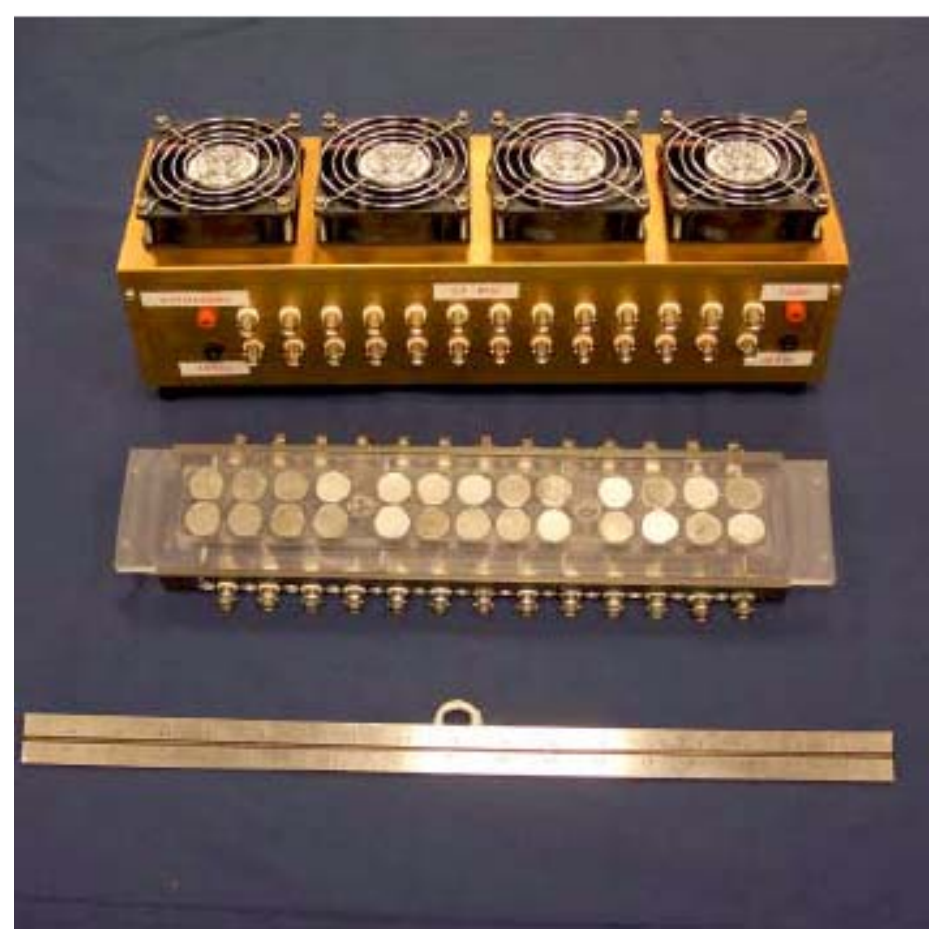

Fig. 3. Photograph of Array B - 2.4 MHz actuators.

- The arrays and the modified Semikron AIPM were taken to ORNL for de testing during October 4-5, 2004. A variety of tests were conducted with both arrays using cooling fluid (WEG mix) at different inlet temperatures. The set-up is shown in the photograph in Fig. 4. The results for both arrays indicate a low cooling potential for the ultrasonic VIBE technology. For Array A (1.65 MHz), the maximum heat-dissipation level was $380 \mathrm{~W}$ at a die temperature of $114^{\circ} \mathrm{C}$ with $105^{\circ} \mathrm{C}$ fluid coming into the device at a flow rate of 1.2 gallons per minute. Changing the flow rate did not significantly impact the heat dissipation performance. In addition to varying the flow rate, the distance between the actuator and heat sink was increased from $5 \mathrm{~mm}$ to $10 \mathrm{~mm}$. This increase in distance also did not affect the heat-dissipation level. The best dissipation level with Array B $\left(2.4 \mathrm{MHz}\right.$ ) was $211 \mathrm{~W}$ at $118^{\circ} \mathrm{C}$ with $105^{\circ} \mathrm{C}$ inlet fluid. 


\section{INTERIM REPORT}

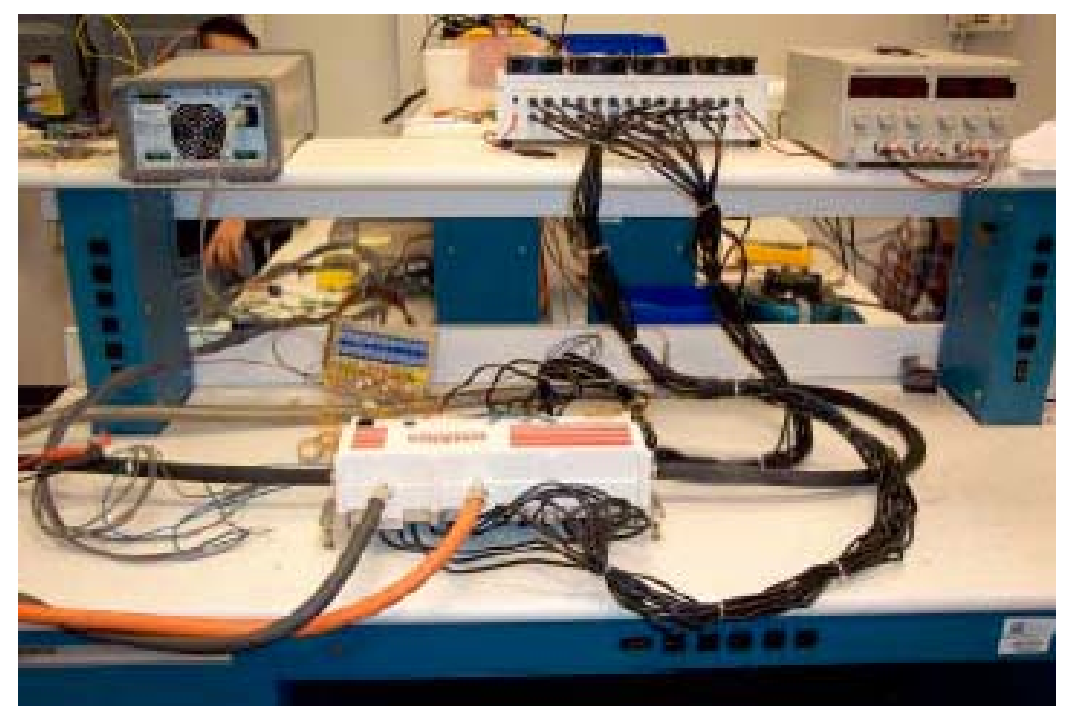

Fig. 4. Photograph of ORNL experimental set-up.

- Several factors contributed to the low-heat dissipation performance of the ultrasonic VIBE technology. Both types of drivers experienced significant corrosion in the WEG environment. Figures 5, 6, and 7 show photographs of the corrosion build-up on both the actuators and the aluminum heat sink. At this time, the exact cause of this corrosion is unknown. It appears on both brass and stainless steel actuators in WEG, but is nonexistent in a pure water environment. Another factor contributing to the poor performance is the inlet fluid temperature constraint. The temperature difference between the die and the fluid is very small (maximum of about $15^{\circ} \mathrm{C}$ ) which limits the potential to remove heat. The geometry and high-flow rates also do not allow for the VIBE technology to shine compared to traditional liquid convection.

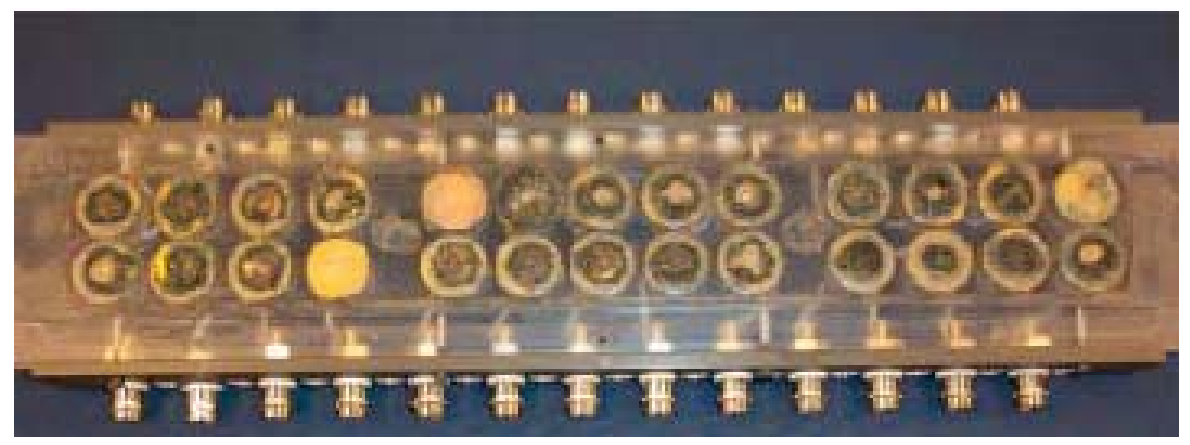

Fig. 5. Photograph of $1.65 \mathrm{MHz}$ actuator corrosion. 


\section{INTERIM REPORT}

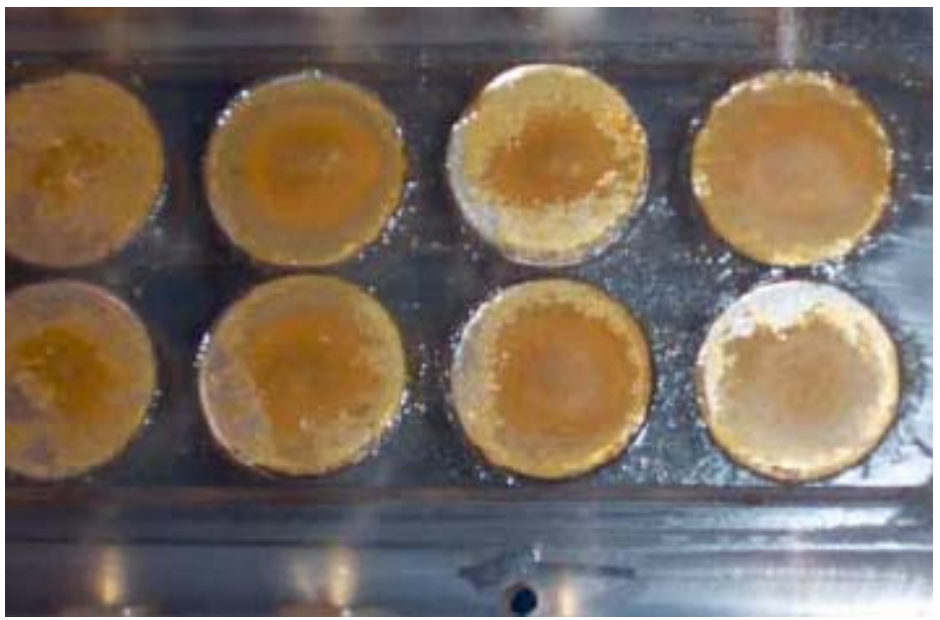

Fig. 6. Photograph of 2.4 MHz actuator corrosion.

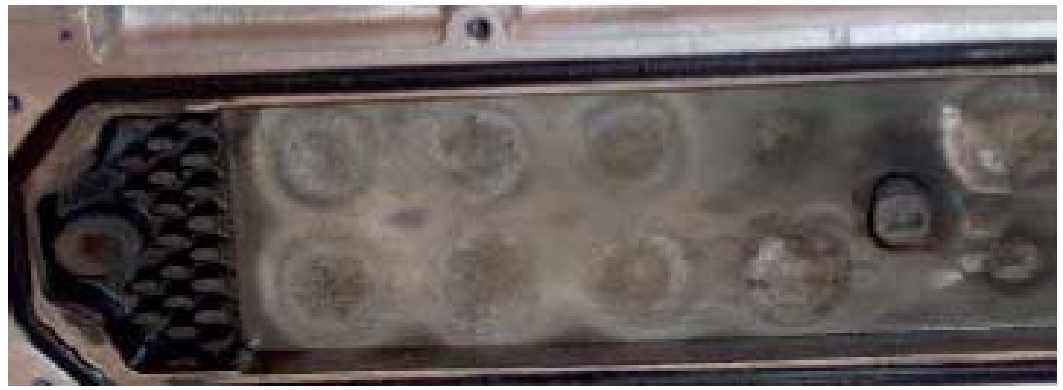

Fig. 7. Photograph of heat-sink corrosion.

- Based on the results of the dc test, it was decided not to build a real AIPM module for testing using the VIBE solution. Innovative Fluidics is interested in doing more fundamental investigations in order to improve the ultrasonic VIBE technology. These studies will result in improvements that could be beneficial to power electronic cooling in the future.

\section{Suggestions for Future Research:}

- Innovative Fluidics plans to continue development of the ultrasonic VIBE technology. The corrosion issue will be investigated. Methods for focusing the ultrasonic energy at the vapor bubbles will also be studied. Detailed measurements of the bubble ejection process and the influence of vibration will be made using microscopic particle image velocimetry. Other factors such as heated surface coating and enhancements will be investigated as well. 


\title{
INTERIM REPORT
}

\subsection{RSC REPORTS}

\subsubsection{Jet Impingement Cooling of a 30/55-kW Semikron Inverter Module}

\section{Jet Impingement Cooling of a 30/55-kW Semikron Inverter Module}

\author{
Avijit Bhunia, Qingjun (Steve) Cai and Chung-Lung Chen \\ Rockwell Scientific Company
}

September 30, 2004

\section{Objective:}

Demonstrate RSC's liquid micro-jet array impingement cooling technique on a Semikron $30 / 55 \mathrm{KW}$ inverter module with the WEG mixture ( $50 \%$ by volume) as the coolant. The specified flow characteristics are: (a) maximum flow rate of $2.5 \mathrm{gpm}$, (b) maximum loop pressure drop of 1.6 bar, and (c) inlet coolant temperature of $105^{\circ} \mathrm{C}$.

$\underline{\text { Progress \& Recent Results: }}$

During the last month we assembled all the flow-loop components. After the initial tests, orifice size on each sprayer had to be modified to meet the pressure drop requirements at 2.5 gpm flow rate. We also tested the immersion pre-heater to raise the inlet coolant temperature close to $105^{\circ} \mathrm{C}$. Figure 1 shows a picture of the overall test bed.

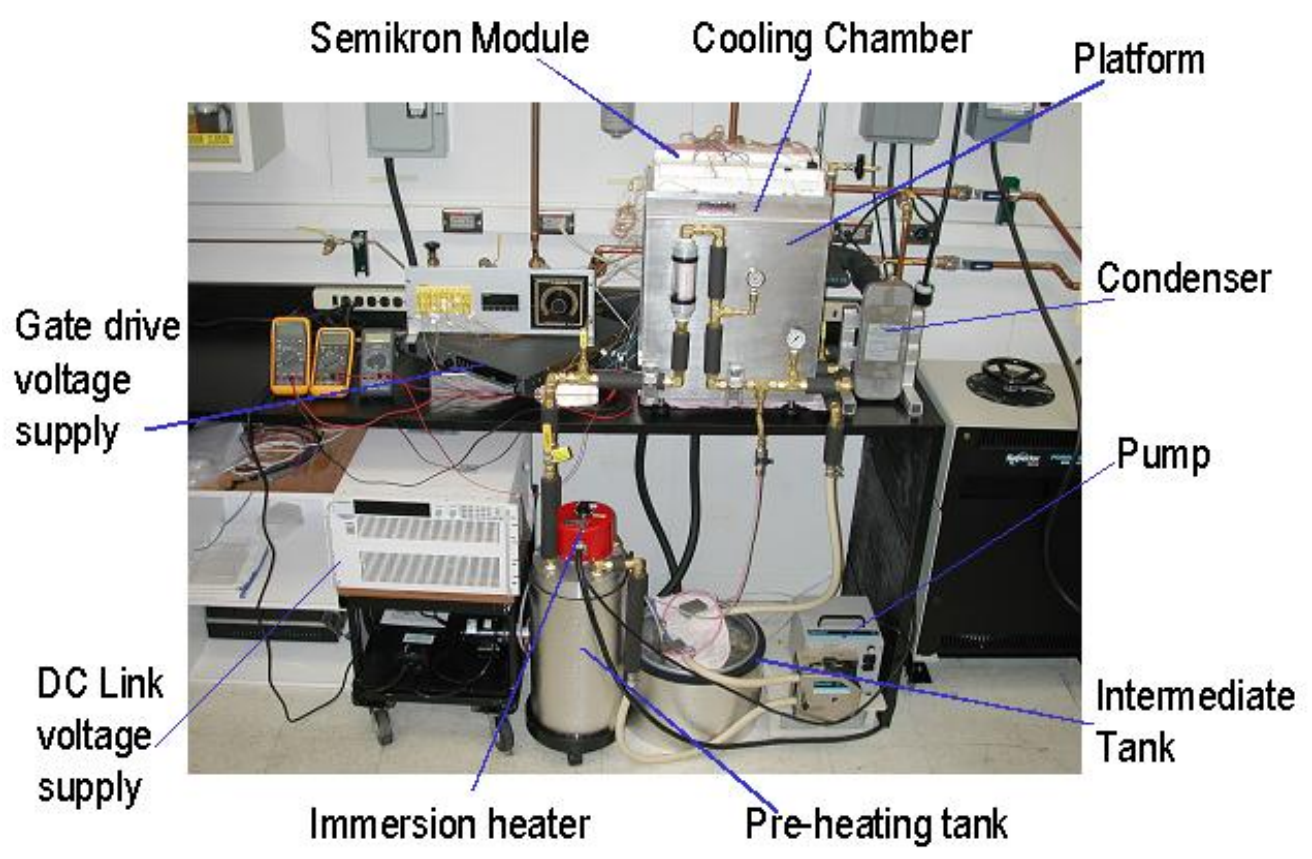

Fig. 1. RSC JIC setup. 
The pressure drop characteristics of the loop at various flow rates are shown in Table 1.

Table 1. Flow rate pressure drop characteristics at various inlet liquid temperatures

\begin{tabular}{|c|c|}
\hline Flow rate $\mathrm{Q}_{\mathrm{L}}($ in gpm) & Pressure drop $\Delta \mathrm{P}(\mathrm{psi})$ \\
\hline 1.0 & $4 \mathrm{psi} @ \mathrm{~T}_{\mathrm{L}}=20^{\circ} \mathrm{C}$ \\
\hline 1.5 & $8 \mathrm{psi} @ \mathrm{~T}_{\mathrm{L}}=20^{\circ} \mathrm{C}$ \\
\hline \multirow{2}{*}{2.0} & $17 \mathrm{psi} @ \mathrm{~T}_{\mathrm{L}}=20^{\circ} \mathrm{C}$ \\
\hline \multirow{2}{*}{2.5} & $19 \mathrm{psi} @ \mathrm{~T}_{\mathrm{L}}=103^{\circ} \mathrm{C}$ \\
\cline { 2 - 2 } & $24 \mathrm{psi} @ \mathrm{~T}_{\mathrm{L}}=20^{\circ} \mathrm{C}$ \\
\hline & $26 \mathrm{psi} @ \mathrm{~T}_{\mathrm{L}}=95^{\circ} \mathrm{C}$ \\
\hline
\end{tabular}

We conducted the first round of dc tests of the module. The gates were turned on with a $24 \mathrm{~V}$ power supply. A $10 \mathrm{~V} 1200 \mathrm{~A}$ power supply was used for the de links. Current through the module was gradually ramped up to $450 \mathrm{~A}$. We collected data at 350 and $450 \mathrm{~A}$ before the module failed. A summary of the measurements at $\mathrm{Q}_{\mathrm{L}}=2 \mathrm{gpm}$ are shown in Table 2.

Table 2. Thermal measurements at $Q_{L}=2 \mathrm{gpm}$, corresponding $\Delta P=19 \mathrm{psi}$

\begin{tabular}{|c|l|l|l|l|l|l|c|}
\hline $\begin{array}{c}\mathrm{T}_{\mathrm{L}} \text {, in } \\
\left({ }^{\circ} \mathrm{c}\right)\end{array}$ & $\begin{array}{c}\text { de link } \\
\text { voltage }\end{array}$ & Current & $\begin{array}{c}\text { Power } \\
\text { dissipated }\end{array}$ & $\begin{array}{c}\text { Max. } \\
\text { IGBT } \\
\text { temp }\end{array}$ & $\begin{array}{c}\text { Min. } \\
\text { IGBT } \\
\text { temp }\end{array}$ & $\begin{array}{c}\text { Junc. to amb. } \\
\text { resistance } \\
\left(\mathrm{R}_{\text {i-amb }}\right)\end{array}$ & $\begin{array}{c}\text { Av. } \mathrm{R}_{\mathrm{j}-} \\
\mathrm{amb} \\
\left({ }^{\circ} \mathrm{c} / \mathrm{W}\right)\end{array}$ \\
\hline 100.2 & $2.23 \mathrm{~V}$ & $350 \mathrm{~A}$ & $783 \mathrm{~W}$ & $113.7^{\circ} \mathrm{C}$ & $112.4^{\circ} \mathrm{C}$ & $0.017^{\circ} \mathrm{C} / \mathrm{W}$ & 0.016 \\
\hline 102.5 & $2.42 \mathrm{~V}$ & $450 \mathrm{~A}$ & $1089 \mathrm{~W}$ & $117.8^{\circ} \mathrm{C}$ & $117.4^{\circ} \mathrm{C}$ & $0.014^{\circ} \mathrm{C} / \mathrm{W}$ & 0.016 \\
\hline
\end{tabular}

At a similar flow rate, $\mathrm{R}_{\mathrm{j} \text {-amb }}$ of Semikron's cold plate is $0.023^{\circ} \mathrm{C} / \mathrm{W}$. Based on our current data, we make projections of power dissipation at $\mathrm{T}_{\mathrm{j}}=125^{\circ} \mathrm{C}$, shown in Table 3 .

Table 3. Estimated heat dissipation capability at $T_{j}$, max $=125^{\circ} \mathrm{C}$ for $2 \mathrm{gpm}$ flow rate

\begin{tabular}{|l|c|c|c|}
\hline $\begin{array}{c}\text { Temperature } \\
\text { conditions }\end{array}$ & $\begin{array}{c}\text { Heat dissipation by } \\
\text { RSC jet } \\
\text { impingement }\end{array}$ & $\begin{array}{c}\text { Heat dissipation by } \\
\text { Semikron cold plate }\end{array}$ & Improvement \\
\hline $\begin{array}{l}\mathrm{T}_{\mathrm{L}, \text { in }}=105^{\circ} \mathrm{C} \\
\mathrm{T}_{\mathrm{j}, \max }=125^{\circ} \mathrm{C}\end{array}$ & $1250 \mathrm{~W}$ & $860 \mathrm{~W}$ & $1.45 \mathrm{X}$ \\
\hline
\end{tabular}

We expect the thermal resistance to reduce further as the evaporation phase change components become more dominant at higher power. Greater than $1250 \mathrm{~W}$ power dissipation is achievable with higher flow rate (up to $2.5 \mathrm{gpm}$ ). A direct DBC level impingement will further improve our cooling performance.

Plan:

After a discussion with Semikron, our initial diagnosis of the module failure seems to be the malfunction of the controller at high temperature. We have shipped the module back to Semikron for a detailed diagnosis. We will continue further experiments to raise the power level after we receive a new module. 


\title{
2.2 Demostration of 30/55-kW Semikron Inverter Module Cooled by Jet-Impingement System
}

\section{Demostration of 30/55-kW Semikron Inverter Module Cooled by Jet Impingement System}

\author{
Final Report \\ Prepared for: \\ Laura D. Marlino \& John Hsu \\ Power Electronics \& Electric Machinery Research Center \\ Engineering Science \& Technology Division \\ Oak Ridge National Laboratory \\ Knoxville, TN \\ Prepared by \\ Avijit Bhunia \& Chung-Lung Chen \\ Applied Computational Physics \& Fluid-Thermal-Acoustics \\ Rockwell Scientific Company, LLC \\ 1049 Camino Dos Rios \\ Thousand Oaks, CA91360 \\ Phone: 805.373.4348, 805.373.4181 \\ Fax: 805.373.4860 \\ abhunia@,rwsc.com, cchen@rwsc.com
}

\section{FEBRUARY 2005}

\section{EXECUTIVE SUMMARY}

As the share of electric power in a hybrid vehicle is projected to grow, the voltage and current ratings of inverter modules will increase. Thermal management of these modules in the harsh environment of automobile will be a challenge. To reduce complexity of the overall system, the automakers are contemplating a single cooling loop for both the engine and the module. Consequently, it is anticipated that the coolant (anti-freeze liquid - WEG 50-50 mixture) available for the module will be at an inlet (ambient) condition of $105^{\circ} \mathrm{C}$. This leaves only a $20^{\circ} \mathrm{C}$ temperature margin between the devices and the ambient as it is desirable to maintain the device temperature lower than $125^{\circ} \mathrm{C}$. Furthermore, the maximum allowable coolant flow rate and pressure drop are restricted to $2.5 \mathrm{gpm}$ and 24 psi respectively. Clearly to go more electric, there is a pressing need for better thermal management techniques capable of handling higher heat flux than the traditional cold-plate (liquid flow over finned heat sink). Rockwell Scientific Company (RSC) has developed a closed loop jet-impingement cooling (JIC) system. The targeted micro-jet array impingement technique is implemented on a $450 \mathrm{~V}$ (dc link voltage) $400 \mathrm{~A}$ (rms current) Semikron module. DC testing of the module with $\sim 105^{\circ} \mathrm{C}$ coolant at 2.25 gpm flow rate (corresponding pressure drop 24 psi) demonstrates 1623 Watts of heat dissipation at an allowable $20^{\circ} \mathrm{C}$ device temperature rise. This translates to a chip level 


\section{INTERIM REPORT}

dissipation power density of $56 \mathrm{~W} / \mathrm{cm}^{2}$, an estimated $1.8 \mathrm{X}$ improvement over the state-of-the-art Semikron's cold plate thermal management scheme. Measurements of the 12 insulated gate bipolar transistors (IGBTs) show a $<3{ }^{\circ} \mathrm{C}$ temperature variation at the highest power level, pointing to a high degree of reliability. Base plate temperature measurements indicate the inception of phase change at $\sim 110-112^{\circ} \mathrm{C}$, i.e., at a low superheat of $\sim 3-5^{\circ} \mathrm{C}$. The average thermal resistance from the junction to base plate and base plate to ambient (based on the total power dissipation) are measured to be $0.0074^{\circ} \mathrm{C} / \mathrm{W}$ and $0.0041^{\circ} \mathrm{C} / \mathrm{W}$ respectively. Evidently, the benefit of phase change based impingement cooling system can be realized to a much greater extent by reduction of the internal thermal resistance, from junction to the base plate.

\section{LIST OF SYMBOLS}

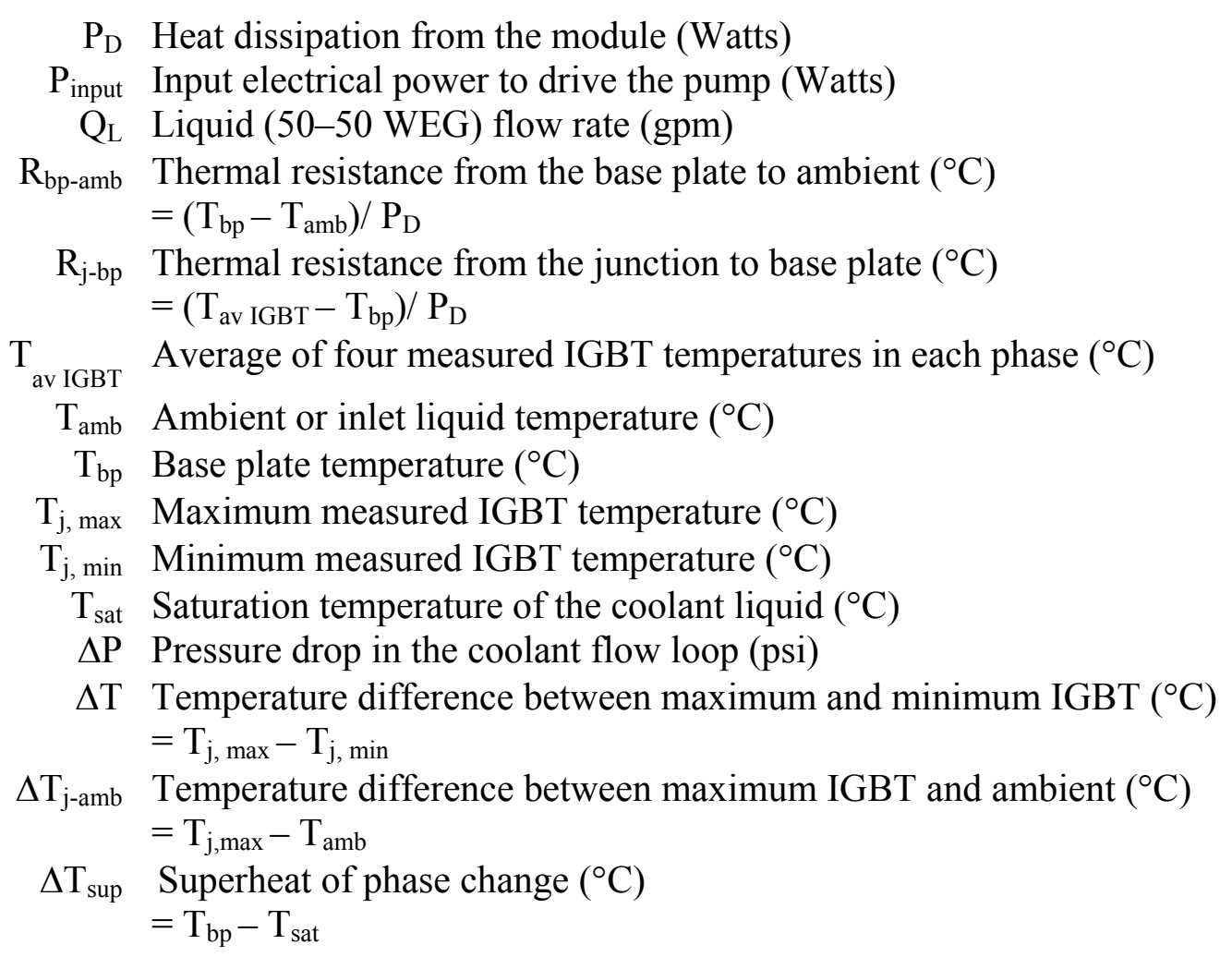




\title{
INTERIM REPORT
}

\subsubsection{Demonstration of 30/55-kW Semikron Inverter Module Cooled by Jet-Impingement System}

\section{Demonstration of 30/55-kW Semikron Inverter Module Cooled by Jet-Impingement System}

\author{
Avijit Bhunia, Qingjun (Steve) Cai, Chung-Lung Chen \\ Rockwell Scientific Company \\ Thousand Oaks, CA
}

\section{PROGRAM OBJECTIVE}

To develop a closed-loop liquid micro-jet array impingement cooling system for demonstration on a $30 / 55 \mathrm{KW}$ inverter module made by Semikron, Rockwell Scientific Company (RSC) proposed to modify the existing Semikron cold plate and implement jet-impingement cooling (JIC) technique at the base plate level.

Keeping the automobile application in mind, the following cooling specifications were prescribed:

- The coolant is anti-freeze liquid, WEG mixture at 50\% volume ratio.

- The inlet coolant (ambient) temperature is $105^{\circ} \mathrm{C}$.

- The device junction temperatures need to be maintained at less than $125^{\circ} \mathrm{C}$. This implies a maximum allowable temperature difference of $20^{\circ} \mathrm{C}$ between the ambient and the device.

- The maximum allowable coolant flow rate is $2.5 \mathrm{gpm}$.

- The maximum allowable pressure drop in the closed-loop cooling system is 1.6 bar (24 psi).

\section{CLOSED-LOOP JIC TEST BED}

\subsection{Power Module}

The JIC system is implemented on a Semikron module SKADS 4001GD06-145x-W. The module is rated for a dc-link voltage of $450 \mathrm{~V}$ and rms current of 400A. Each of the three phases of the module has 12 IGBT dies and 6 diode dies. The typical dimension of each of these dies is $9 \mathrm{~mm} \times 9 \mathrm{~mm}$. Figure 1(a) and (b) respectively show an exploded view of the module and the layout of devices on each DBC board. The existing cooling technique is forced convection liquid flow through the pin fin heat sink at the base plate of the module (Fig. 1(c)). Overall dimension of the module with the existing heat sink is $400 \mathrm{~m} \times 215 \mathrm{~mm} \times 100 \mathrm{~mm}$. 


\section{INTERIM REPORT}

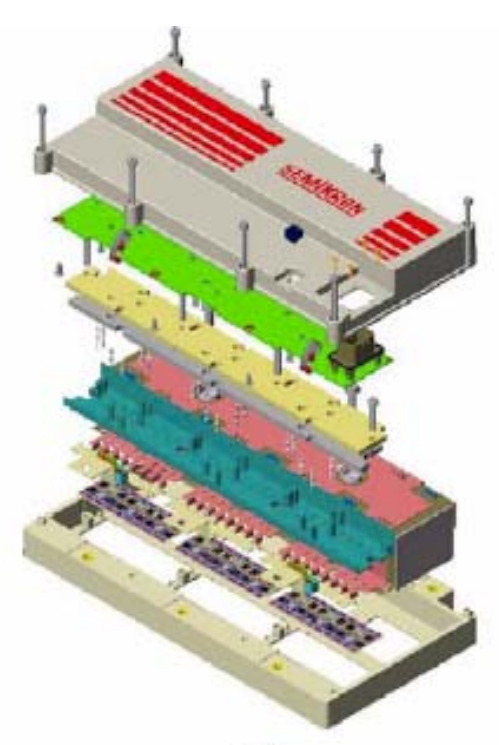

(a)

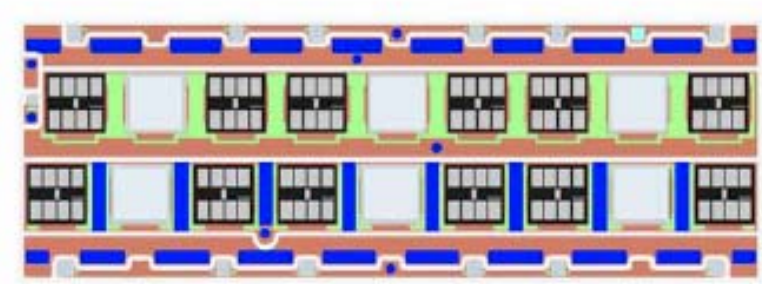

(b)

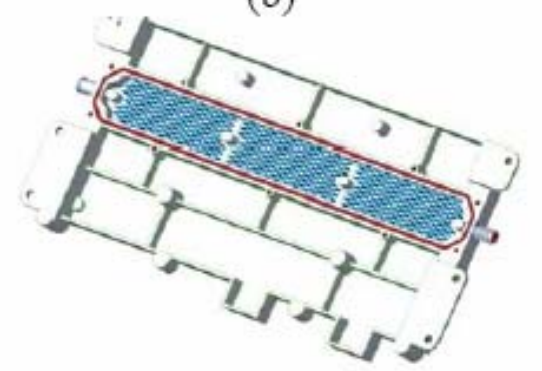

(c)

Fig. 1. (a) Exploded view of Semikron's module SKADS4001GD06-145x-W,

(b) Layout of 12 IGBT dies and 6 diode dies on the DBC board of each phase leg, and (c) Base plate with pin fins for liquid flow cooling.

For testing the thermal management scheme, the module is operated in a dc mode. As a result only the IGBTs dissipate power. Gates of the IGBTs are maintained at "always on" condition by a $24 \mathrm{~V}$ dc power supply. A $10 \mathrm{~V} 1200 \mathrm{~A}$ dc power supply is used for power input to the dc links. In absence of an external load, the entire power input to the module is dissipated as heat through the 36 IGBTs. Device temperatures are measured by attaching K type thermocouples on the IGBTs and diodes. In each phase, temperatures are measured on 4 IGBTs and 2 diodes, resulting in a total of 12 IGBT temperature measurements.

\subsection{Closed Loop Micro-jet Array Impingement Cooling System}

Figure 2 shows a schematic of the closed loop cooling system. 


\section{INTERIM REPORT}

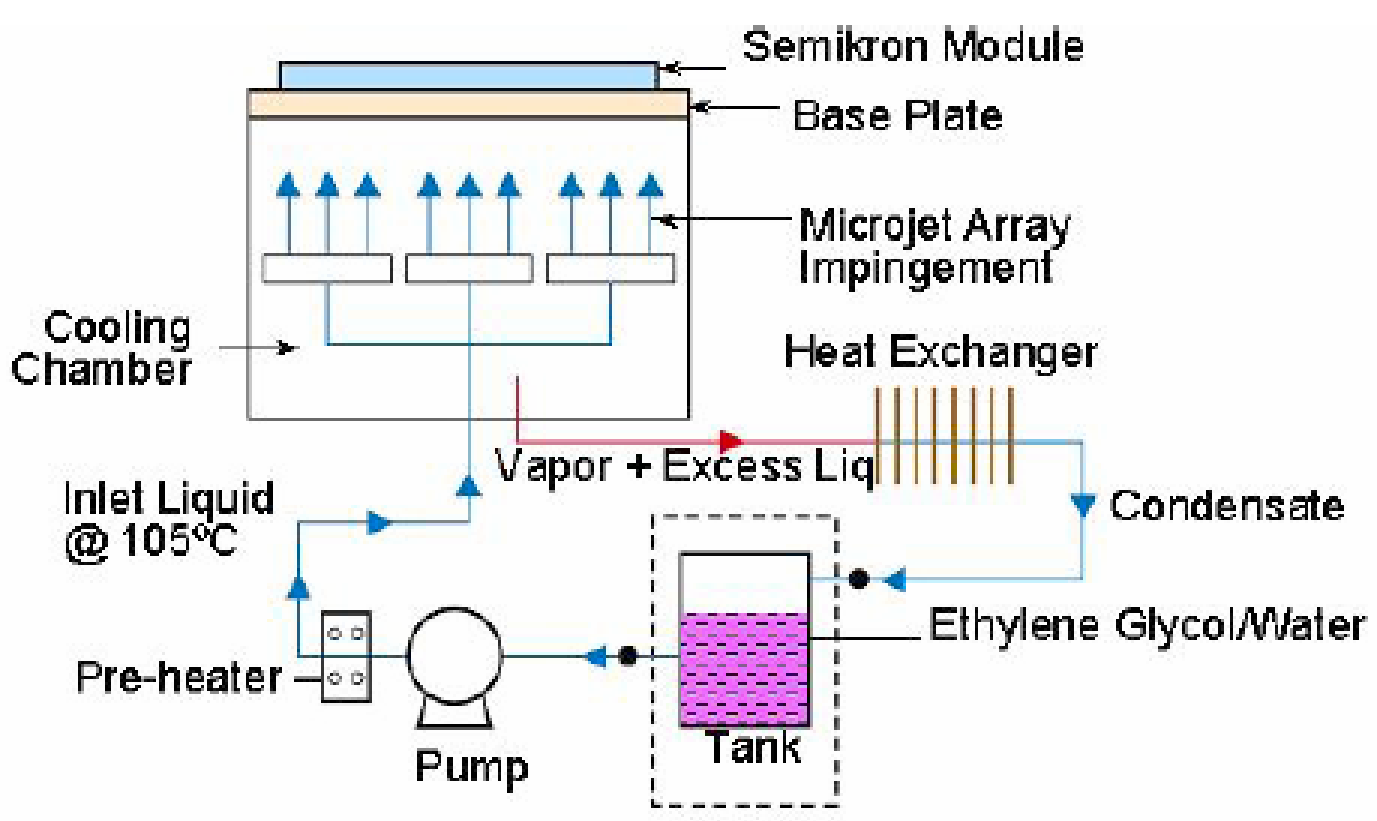

Fig. 2. A schematic of the closed loop liquid micro-jet array impingement cooling system for the Semikron module.

The cooling chamber is conformal to the module base plate. The micro-jet array impinges at the base plate of the module, targeted at the footprint location of the devices, underneath each IGBT. To reduce the thermal resistance through the base plate, slot openings are made in the base plate underneath each IGBT, as shown in the schematic in Fig. 3. The base plate thickness at the impingement location is $1 \mathrm{~mm}$. Three $1.2 \mathrm{~mm}$ diameter and $83 \mathrm{~mm}$ deep blind holes are drilled into the base plate underneath each DBC board, and thermocouples are inserted to measure the base plate temperatures $\left(\mathrm{T}_{\mathrm{bp}}\right)$, one for each phase. The overall dimensions of the base plate are: $423 \mathrm{~mm} \times 245 \mathrm{~mm} \times 15 \mathrm{~mm}$.

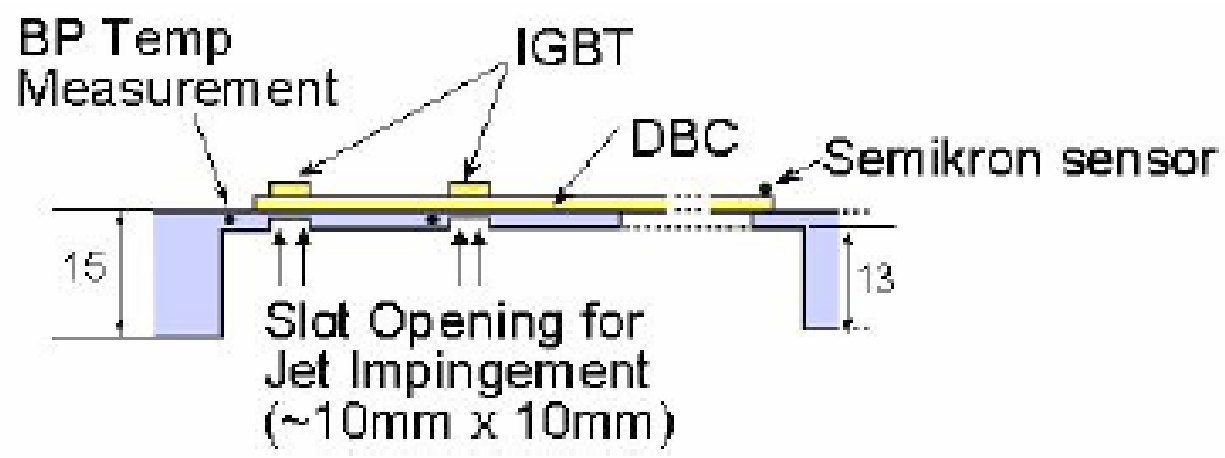

Fig. 3. Base plate modification for targeted micro-jet array impingement underneath each IGBT.

The cooling chamber, shown in Fig. 2, houses three liquid distribution manifolds corresponding to the three phases. Each distribution manifold has a total of 12 clusters of impingement pattern, with 5 orifices per cluster (average diameter $293 \mu \mathrm{m}$ ) for each IGBT. For each distribution manifold, a $75 \mu \mathrm{m}$ filter is used to avoid clogging of the micro-orifices. The average liquid temperature $\left(\mathrm{T}_{\mathrm{amb}}\right)$, measured at the inlet of each distribution manifold, is 


\section{INTERIM REPORT}

$104.3^{\circ} \mathrm{C}$. The overall dimensions of the cooling chamber are: $423 \mathrm{~mm} \times 245 \mathrm{~mm} \times 38 \mathrm{~mm}$. It is to be noted that the current design is not optimized. There is a definite scope of reducing the chamber size towards a more compact system.

A peristaltic pump capable of delivering flow rate $\left(\mathrm{Q}_{\mathrm{L}}\right)$ up to $3.4 \mathrm{gpm}$ at a pressure drop up to $35 \mathrm{psi}$ is chosen. Since $\mathrm{T}_{\mathrm{amb}}$ is $\sim 105^{\circ} \mathrm{C}$, very close to the saturation temperature $\left(\mathrm{T}_{\text {sat }}\right)$ of $107^{\circ} \mathrm{C}$, the pump is prone to cavitation due to local boiling. Handling two-phase flow degrades the performance of any pump, especially the direct liquid contact centrifugal or gear pumps. A peristaltic pump is relatively less susceptible to this problem as the liquid does not come in contact with the pump gears (rotating mechanism).

To further reduce the chance of cavitation, liquid temperature at the heat exchanger outlet is maintained at a temperature $\sim 10^{\circ} \mathrm{C}$ below $\mathrm{T}_{\text {sat }}$. To simulate the car engine in the real automobile application scenario a pre-heater is used. An immersion heater of $6 \mathrm{KW}$ rating and temperature controllability up in the range of $38^{\circ} \mathrm{C}$ to $121^{\circ} \mathrm{C}$ is chosen. The heat exchanger has to dissipate the heat input at the pre-heater and from the module. A $15 \mathrm{KW}$ capacity water-cooled heat exchanger is used. Figure 4 shows a picture of the experimental setup.

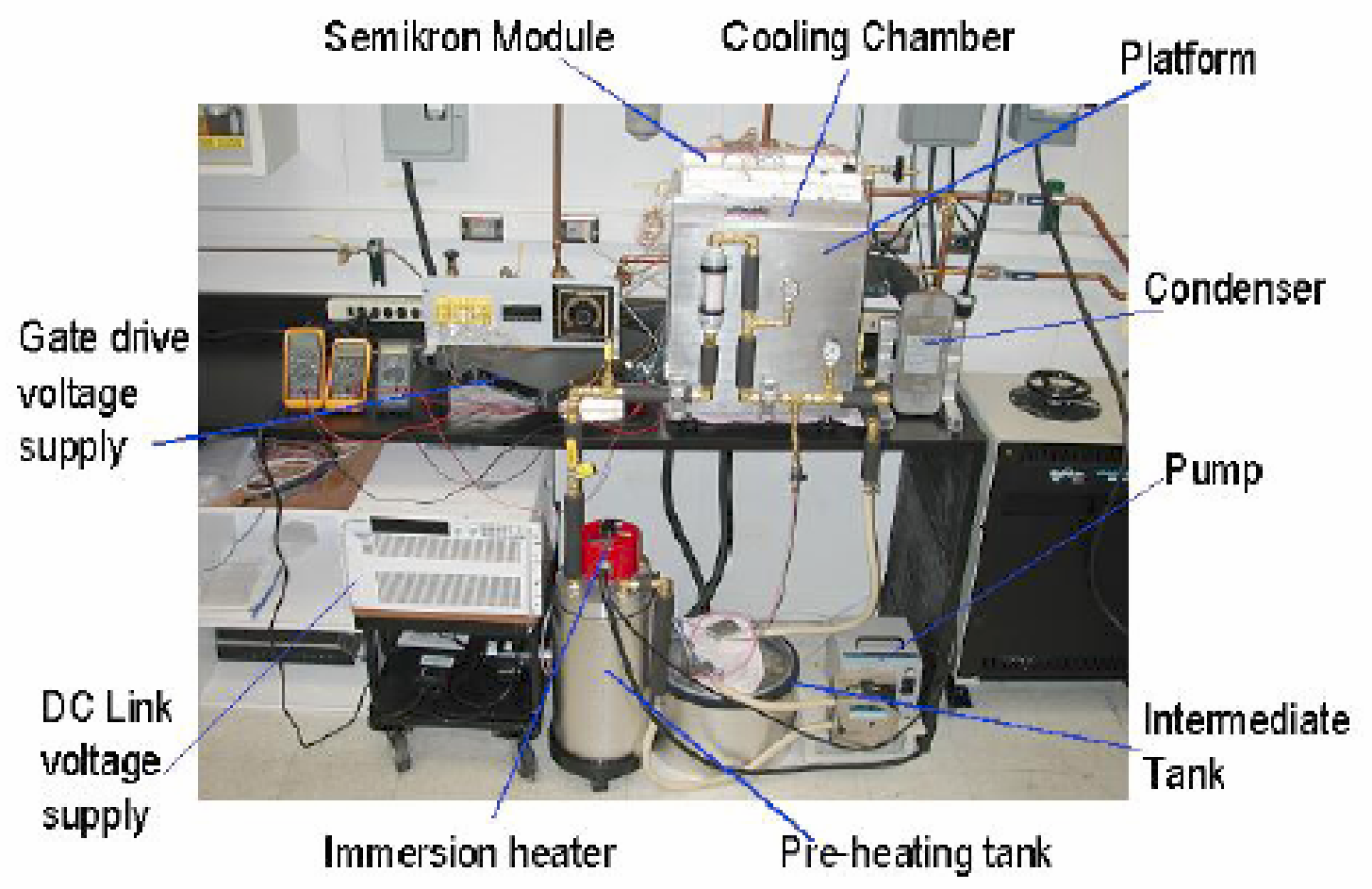

Fig. 4. Closed loop jet-impingement cooling setup.

The experimental flow rate regime has to be chosen based on the overall pressure drop requirement of 1.6bar ( $24 \mathrm{psi})$. Before powering the module, a series of flow-loop experiments are carried out to characterize the system pressure drop $(\Delta \mathrm{P})$. The system pressure drop is observed to increase with operating temperature. The pre-heater is used to heat the liquid up to the prescribed inlet temperature of $105^{\circ} \mathrm{C}$. The results are summarized in Table 1. 


\section{INTERIM REPORT}

Table 1. Closed loop system pressure drop at different flow rates. Inlet liquid temperature $\left(T_{\mathrm{amb}}\right.$ ) is maintained at $\sim 105^{\circ} \mathrm{C}$.

\begin{tabular}{|c|c|}
\hline Flow rate $\mathrm{Q}_{\mathrm{L}}(\mathrm{gpm})$ & Pressure drop $\Delta \mathrm{P}(\mathrm{psi})$ \\
\hline 1.5 & 10 \\
\hline 1.75 & 13.5 \\
\hline 2 & 19 \\
\hline 2.25 & 24 \\
\hline 2.5 & 28 \\
\hline
\end{tabular}

Experiments are performed for three different flow rates of $1.75,2$, and $2.25 \mathrm{gpm}$. The electrical input power to the pump $\left(\mathrm{P}_{\text {input }}\right)$ at these flow rates measured by a handheld power meter, are 69,87, and 120Watts respectively. The dc link power supply is operated at a constant current mode. Ramping up the current setting of the power supply gradually increases the module power dissipation. The forward voltage drops in the upper and lower switches are measured for each of the three phases. At each power level, a total of 24 temperature measurements (4 IGBTs, 2 Diodes, the base plate, and the liquid inlet for each phase) are carried out using a multi-channel thermocouple reader.

The experimental uncertainties in measuring power dissipation, flow rate, temperature, and pressure are $8.1 \%, 4.9 \%, 3 \%$, and $5 \%$ respectively.

\section{RESULTS \& DISCUSSION}

The primary evaluation criterion for the cooling technique is its power dissipation $\left(\mathrm{P}_{\mathrm{D}}\right)$ capability and the corresponding maximum device junction temperature $\left(T_{j}\right.$, max $)$. The rise of $\mathrm{T}_{\mathrm{j} \text {, max }}$ over the ambient condition $\left(\Delta \mathrm{T}_{\mathrm{j}-\mathrm{amb}}=\mathrm{T}_{\mathrm{j} \text {, max }}-\mathrm{T}_{\mathrm{amb}}\right)$ at various $\mathrm{P}_{\mathrm{D}}$ levels is shown in Fig. 5. As anticipated, $\Delta \mathrm{T}_{\mathrm{j} \text {-amb }}$ increases with $\mathrm{P}_{\mathrm{D}}$ and the trend is observed to be linear. At any $\Delta \mathrm{T}_{\mathrm{j} \text {-amb }}$, the increase in $\mathrm{P}_{\mathrm{D}}$ with flow rate $\left(\mathrm{Q}_{\mathrm{L}}\right)$ is per expectation too. With the prescribed limits of $\mathrm{T}_{\mathrm{amb}}=$ $105^{\circ} \mathrm{C}$ and $\mathrm{T}_{\mathrm{j}, \max }<125^{\circ} \mathrm{C}$, of particular interest is the $\Delta \mathrm{T}_{\mathrm{j} \text {-amb }}=20^{\circ} \mathrm{C}$ condition. The maximum power dissipation capability of JIC are observed to be $1495 \mathrm{~W}, 1583 \mathrm{~W}$, and $1623 \mathrm{~W}$ respectively for $\mathrm{Q}_{\mathrm{L}}=1.75,2$, and $2.25 \mathrm{gpm}$. The corresponding average chip level dissipation power densities are 51,54 , and $56 \mathrm{~W} / \mathrm{cm}^{2}$. Enhancement in performance from $\mathrm{Q}_{\mathrm{L}}=2$ to $2.25 \mathrm{gpm}$ seems to be nominal, especially in light of the significant increase in pump input power $\left(\mathrm{P}_{\text {input }}\right)$.

Thermal tests of traditional forced convection flow through a cold plate with pin fins shown in Fig. 1(c) conducted by Semikron are at $\mathrm{T}_{\mathrm{amb}}=70^{\circ} \mathrm{C}$. With first order correction for change in liquid properties, the estimated cold-plate heat dissipation capability is $\sim 894 \mathrm{~W}$ at $\mathrm{T}_{\mathrm{amb}}$ $=105^{\circ} \mathrm{C}$ and $\mathrm{Q}_{\mathrm{L}}=2.25 \mathrm{gpm}$. Thus $\mathrm{JIC}$ demonstrates a $1.8 \mathrm{X}$ improvement in thermal performance. 


\section{INTERIM REPORT}

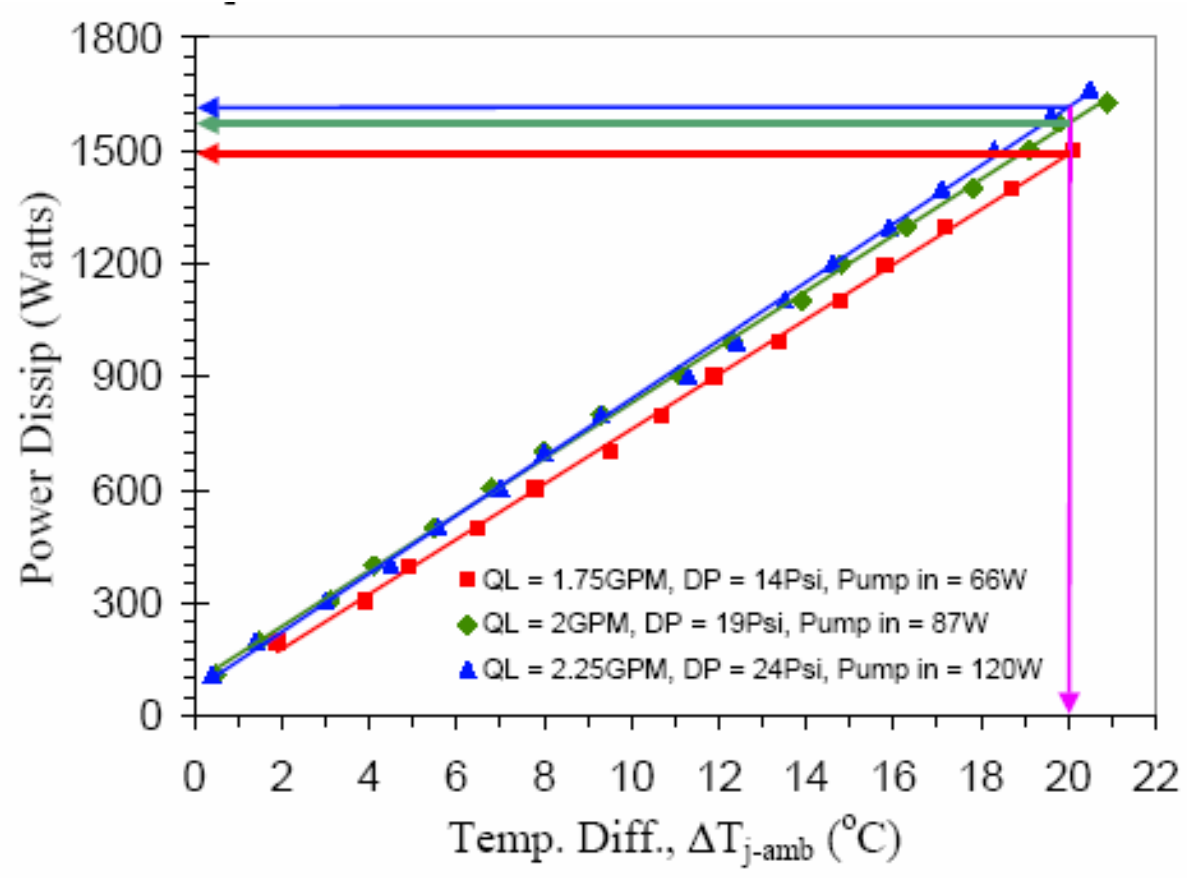

Fig. 5. Variation of power dissipation $\left(P_{D}\right)$ with maximum temperature difference between device junction $\left(T_{j, \text { max }}\right)$ and ambient $\left(T_{a m b}\right)$; average $T_{a m b}=104.3^{\circ} \mathrm{C}$; flow rate $Q_{L}=1.75,2$, and $2.25 \mathrm{gpm}$.

Variation of junction temperature among the devices (non-uniformity) is an important parameter impacting reliability of the inverter module and the three-phase alternating-current (ac) motor it drives. Therefore, the difference between the maximum $\left(T_{j}\right.$, max $)$ and minimum $\left(T_{j}\right.$, min $)$ of the 12 measured IGBT temperatures $(\Delta T)$ in three-phases is monitored at various $P_{D}$ conditions, as shown in Fig. 6. Although the data appears to be somewhat scattered, the increasing tendency of $\Delta \mathrm{T}$ with $\mathrm{P}_{\mathrm{D}}$ is obvious, both from the experimental measurements as well as the linear trend line. As expected, the non-uniformity of temperature is reduced with increasing flow rate. At $\mathrm{P}_{\mathrm{D}}=1623 \mathrm{~W}, \Delta \mathrm{T}$ is observed to be less than $3^{\circ} \mathrm{C}$ or $2.5 \%$ of the absolute temperature. 


\section{INTERIM REPORT}

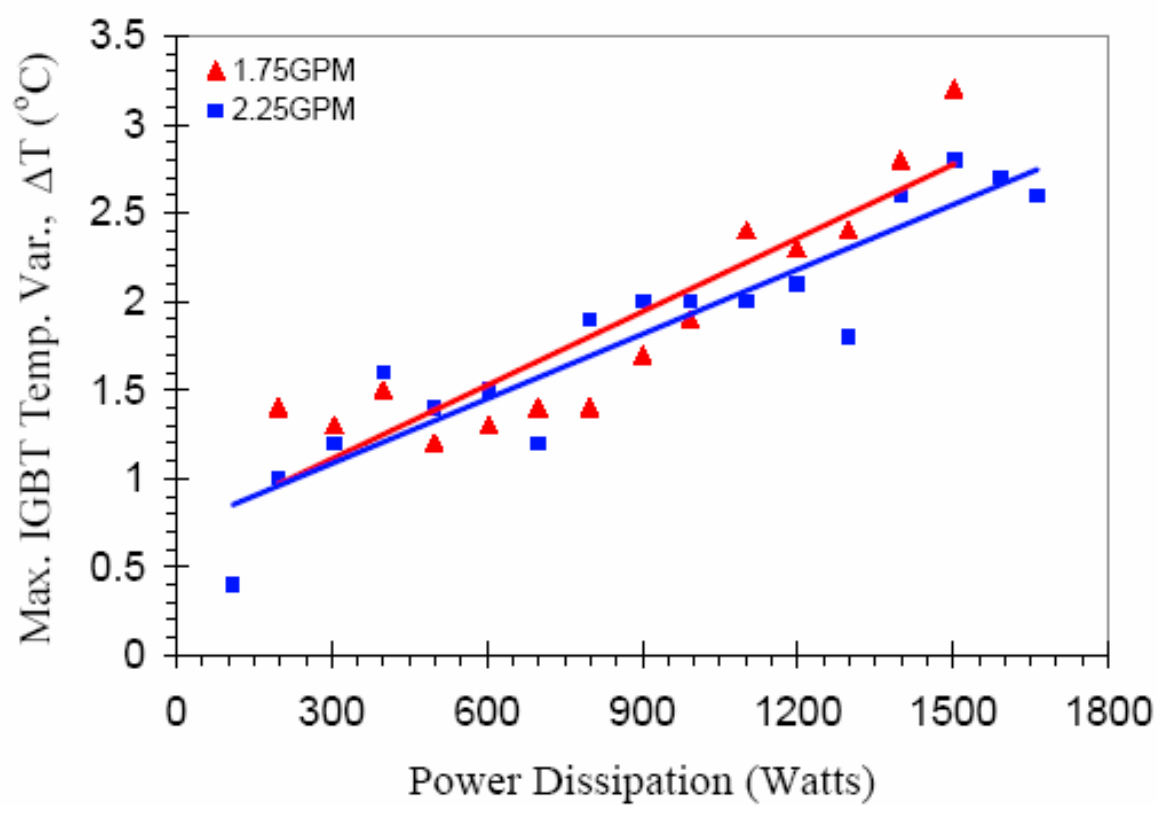

Fig. 6. IGBT temperature variation $\left(\Delta T=T_{j, \max }-T_{j, \min }\right)$ vs. power dissipation $\left(P_{D}\right)$ at $Q_{L}=1.75$ and $2.25 \mathrm{gpm}$.

Three factors can contribute to the non-uniformity of temperature. (1) The experimental measurements of the total forward voltage drop at the upper and lower switches show up to $0.5 \%$ variation among the three phases. Thus, there is non-uniformity in power sharing among the phases. (2) The flow distribution among the three impingement chambers for three phases may not be uniform. Even within a chamber, there could be non-uniformity among the clusters of micro-jets due to local clogging or pressure drop inside the impingement chamber. (3) It will be shown later that the base plate temperature $\left(\mathrm{T}_{\mathrm{bp}}\right)$ in most of the experimental condition hovers around the saturation temperature $\left(\mathrm{T}_{\text {sat }}\right)$ of the liquid. Close to the onset of phase change (boiling), local rise or drop in temperature is possible based on the surface condition. Such change in $\mathrm{T}_{\mathrm{bp}}$ will affect the device temperature too.

Base plate temperature $\left(\mathrm{T}_{\mathrm{bp}}\right)$ measurements underneath the phase-I DBC board at various $\mathrm{P}_{\mathrm{D}}$ levels are shown in Fig. 7 for three different $\mathrm{Q}_{\mathrm{L}}$ conditions. The red line at the inset picture of Fig. 7 shows the relative location of the $T_{b p}$ measurement with respect to the devices. The variation of $\mathrm{T}_{\mathrm{bp}}$ is too little to comment on the effect of $\mathrm{Q}_{\mathrm{L}}$. However, for all three flow rates, changes in slope of the curves at $\mathrm{P}_{\mathrm{D}} \sim 850-1100 \mathrm{~W}$ (corresponding $\mathrm{T}_{\mathrm{bp}} \sim 110-111^{\circ} \mathrm{C}$ ) are evident. This indicates onset of phase change at a low superheat $\left(\Delta \mathrm{T}_{\text {sup }}=\mathrm{T}_{\mathrm{bp}}-\mathrm{T}_{\text {sat }}\right)$ of $\sim 3-4^{\circ} \mathrm{C}$. An early stage of phase change heat transfer is observed beyond $\mathrm{P}_{\mathrm{D}} \sim 1100 \mathrm{~W}$. Cost involved in the labor intensive drilling of the thermocouple holes prevented us from more detailed base plate temperature measurements that could give further insight into the spatial characteristics of the phase change process. 


\section{INTERIM REPORT}

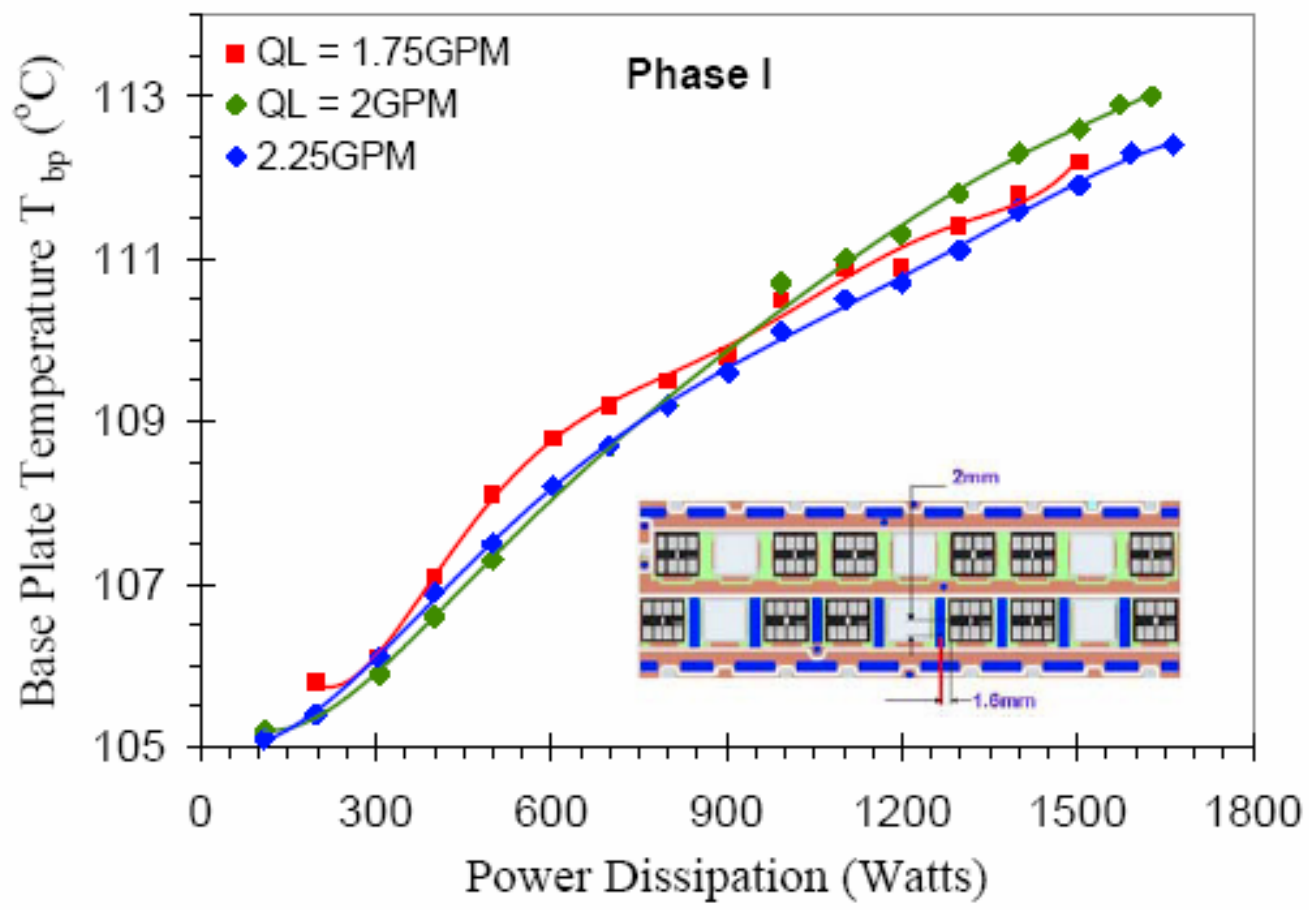

Fig. 7. Variation of base plate temperature $\left(T_{b p}\right)$ underneath the phase-I DBC vs. power dissipation $\left(P_{D}\right)$ at flow rates $\left(Q_{L}\right)=1.75,2$, and $2.25 \mathrm{gpm}$.

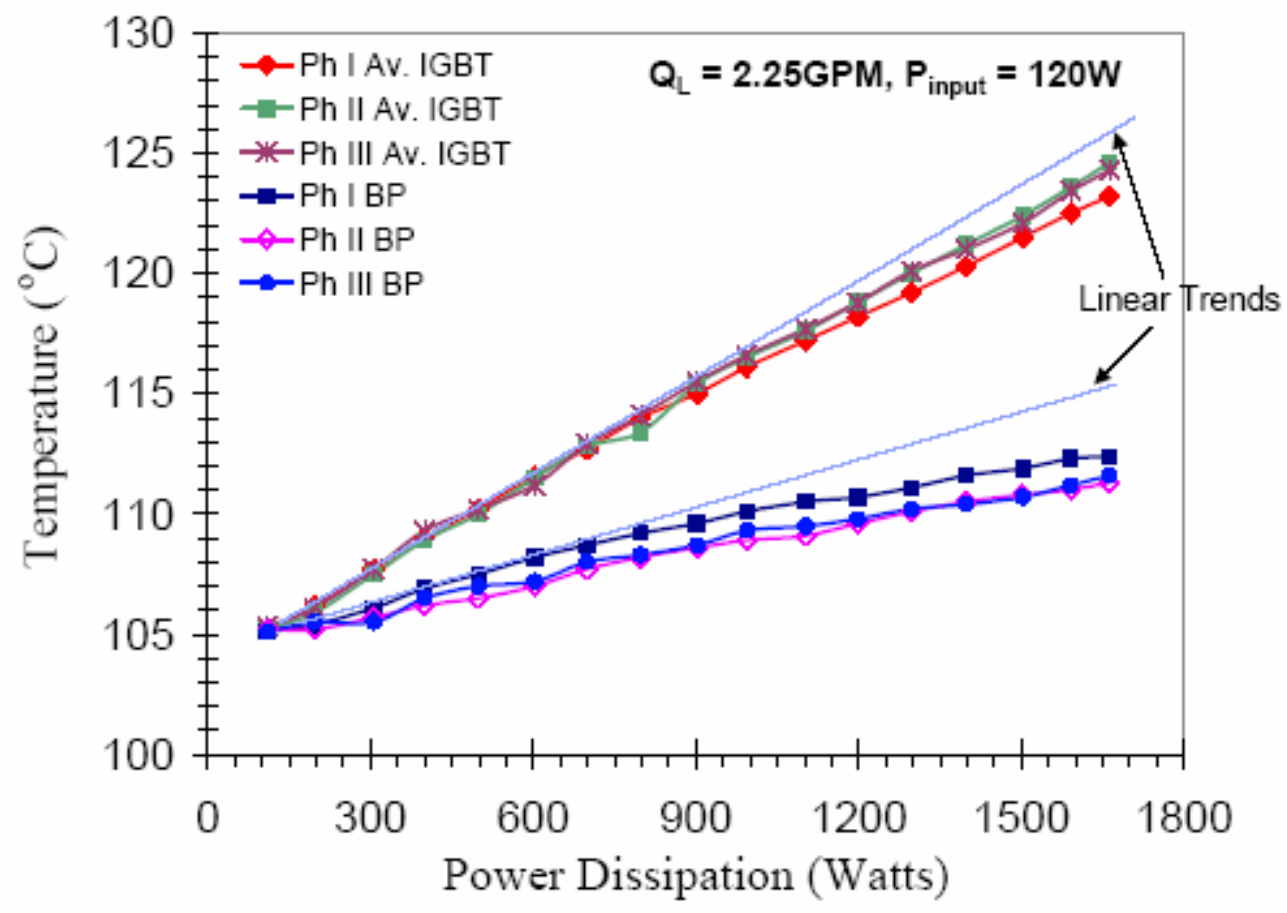

Fig. 8. Variation of base plate and average IGBT temperatures among the three phases at flow rate $Q_{L}=2.25 \mathrm{gpm}$. 


\section{INTERIM REPORT}

At any given flow rate, the variation of the base plate and IGBT temperatures among the three phases are shown in Fig. 8. IGBT temperatures $\left(\mathrm{T}_{\mathrm{av}}\right.$ IGBT $)$ shown here are the average of four measurements for each phase. The slight variation in temperature measurements among the three phases could be due to any of the three reasons outlined in the discussion of Fig. 6. Linear trends based on the early parts of the curve $\left(\mathrm{P}_{\mathrm{D}}<\sim 900 \mathrm{~W}\right)$ are superimposed on Fig. 8 for both $\mathrm{T}_{\mathrm{bp}}$ and $\mathrm{T}_{\mathrm{av}}$ IGBT plots. The change in $\mathrm{T}_{\mathrm{bp}}$ curve slope near $\sim 109^{\circ} \mathrm{C}$ is a clear indication of the inception of phase change. It is further observed that the lowering of $\mathrm{T}_{\mathrm{bp}}$ by phase change is not propagated to the $\mathrm{T}_{\mathrm{av} \text { IGBT }}$ values in the same proportion. This is due to a high internal thermal resistance from the IGBT junction to the base plate $\left(R_{j-b p}=\left[T_{a v}\right.\right.$ IGBT $\left.\left.-T_{b p}\right] / P_{D}\right)$, compared to the cooling thermal resistance from base plate to ambient $\left(\mathrm{R}_{\mathrm{bp}-\mathrm{amb}}=\left[\mathrm{T}_{\mathrm{bp}}-\mathrm{T}_{\mathrm{amb}}\right] / \mathrm{P}_{\mathrm{D}}\right)$. The average resistances of the three phases, from junction to base plate $\left(\mathrm{R}_{\mathrm{j} \text {-bp }}\right)$ and the base plate to ambient $\left(\mathrm{R}_{\text {bp-amb }}\right)$ are $0.0074 \mathrm{C} / \mathrm{W}$ and $0.0041 \mathrm{C} / \mathrm{W}$ respectively. Evidently the benefit of phase change based impingement cooling system can be realized to a much greater extent by reduction of the internal thermal resistance.

\section{SYSTEM IMPLEMENTATION \& RELIABILITY}

Heat exchange with the ambient: The under hood ambient air temperature $\left(\mathrm{T}_{\text {air }}\right)$ condition in the automobile is anticipated to vary between $-40^{\circ} \mathrm{C}$ to $140^{\circ} \mathrm{C}$. This will lead to heat loss from the module base plate and cooling chamber wall (total area $=686 \mathrm{~cm}^{2}$ ) for $\mathrm{T}_{\text {air }}=-40^{\circ} \mathrm{C}$ or heat gain from the ambient air (additional heat load to be cooled by liquid impingement) when $\mathrm{T}_{\text {air }}$ is $140^{\circ} \mathrm{C}$. It is important to judge the magnitude of this heat load to assess the necessity of insulation on the power module and the cooling system. A thermocouple attached to various locations of the base plate and cooling chamber wall during the experiment indicate an average surface temperature of $\sim 70^{\circ} \mathrm{C}$ for the inlet liquid temperature of $105^{\circ} \mathrm{C}$ and base plate temperature (near the device) of $\sim 112^{\circ} \mathrm{C}$. The heat transfer mechanism is assumed to be natural convection. Heat loss from the walls at $\mathrm{T}_{\text {air }}=-40^{\circ} \mathrm{C}$ is estimated to be $73 \mathrm{~W}, \sim 4.5 \%$ of the total heat load dissipated by impingement cooling. For $\mathrm{T}_{\text {air }}=140^{\circ} \mathrm{C}$, the heat gain into the module is estimated to be $39 \mathrm{~W}$, i.e., an additional $2.4 \%$ of the dissipated power.

While the JIC system provides a much better thermal performance compared to the cold plate, a discussion on the system components is warranted in the light of robustness, reliability, maintenance requirement, and cost. Keeping the automobile application in mind, these are practical aspects that can put constraints even on the most exotic thermal management solution. In the JIC system, the micro-jet array and the pump are the two vital components that need particular attention.

Micro-jets: The biggest concern is clogging of the micro-orifices that produce these jets. An in-line strainer with $75 \mu \mathrm{m}$ filter size (compared to average orifice diameter of $293 \mu \mathrm{m}$ ) used in the present experiment significantly reduces the risk. At the initial stages of the experiments, the strainer filters had to be cleaned at regular intervals. As it is a closed-loop system with a few initial runs, the particles were mostly trapped and pressure rouse due to clogging were virtually eliminated during the course of the experiment. In a practical automobile system, it is anticipated that this initial loop cleaning will be completed in the factory itself. Subsequently it can become 


\section{INTERIM REPORT}

a cheap routine maintenance work every few thousand miles. Localized individual orifice clogging remains a possibility (although low) that can trigger temperature overshoot of a single device. Increasing the number of orifices per device will make the system more redundant and enhance the reliability considerably.

The cost of production of these micro-orifices is another aspect. Currently we are using conventional micro-drills and a CNC machine. Because of the labor-intensive nature of the job, the cost is high on a single unit basis. Mass production by injection molding or die casting is possible and can bring the cost to a very practical level.

Selection of Pump: As discussed earlier, the ambient (inlet liquid) condition of $105^{\circ} \mathrm{C}$ and liquid saturation temperature of $107^{\circ} \mathrm{C}$ makes the pump susceptible to cavitation. To avoid this issue, we have used a peristaltic pump with flexible tubing that can handle two-phase (vapor, liquid mixture) without imminent damage to the pump gears. However, the peristaltic pumps are expensive $(\sim 2000)$ and the long-term use of flexible tubing in the automobile platform is a reliability concern too. Use of a conventional centrifugal or gear pump with rigid tubing resolves these concerns, but careful system design is necessary to avoid cavitation. With a proper overall system consideration, if the heat exchanger outlet temperature can be reduced to $\sim 80-90^{\circ} \mathrm{C}$ (significantly lower than the saturation condition), possibility of cavitation is greatly reduced.

\section{CONCLUDING REMARKS}

In this project RSC developed a closed loop JIC technique for automobile inverter module cooling application. A system demonstration is performed by implementing the targeted micro-jet array impingement on a 450V (dc link voltage) 400A (rms current) Semikron module. The stringent program requirements of $105^{\circ} \mathrm{C}$ inlet coolant temperature, $<125^{\circ} \mathrm{C}$ maximum device temperature, $<2.5 \mathrm{gpm}$ flow rate and cooling loop pressure drop $<1.6$ bar ( $24 \mathrm{psi}$ ) are all met satisfactorily. RSC concludes the project with a demonstration of 1623 Watts of heat dissipation from the module, an estimated 1.8X improvement over the state-of-the-art Semikron's cold plate. We show that the JIC technique is capable of meeting the grand challenge of inverter module cooling in the harsh automobile environment and can provide a compact thermal management solution.

\section{FUTURE WORK}

In the course of this project, we have identified a number of heat transfer augmentation techniques that can enhance the module performance. Some examples are: direct DBC level impingement; impingement surface modification; optimizing jet size and number of jets per hot spot (device); reduction of system pressure; etc. Each of these aspects requires further research.

Of particular interest is the direct DBC level impingement through cutouts in the base plate, a schematic concept of which was shown during RSC's presentation in the Tech meeting at Detroit on July 22, 2004. Our initial calculations show that the internal thermal resistance (device junction to impingement surface) can be reduced by as much as $60 \%$ by direct DBC level impingement. 


\section{INTERIM REPORT}

To take this promising technique from laboratory scale breadboard demonstration to practical automobile application, investigation of some practical aspects is necessary. For example: modification of the impingement pattern to incorporate both diode and IGBT cooling; draining of the excess liquid from cooling chamber and from the condenser outlet to the intermediate tank; verifying the necessity of an intermediate tank and its optimum sizing; and "gravity-independent" optimum impingement distance for compact cooling chamber design. 


\section{INTERIM REPORT}

\subsection{ISR REPORTS}

\section{ISR SprayCool Solutions}

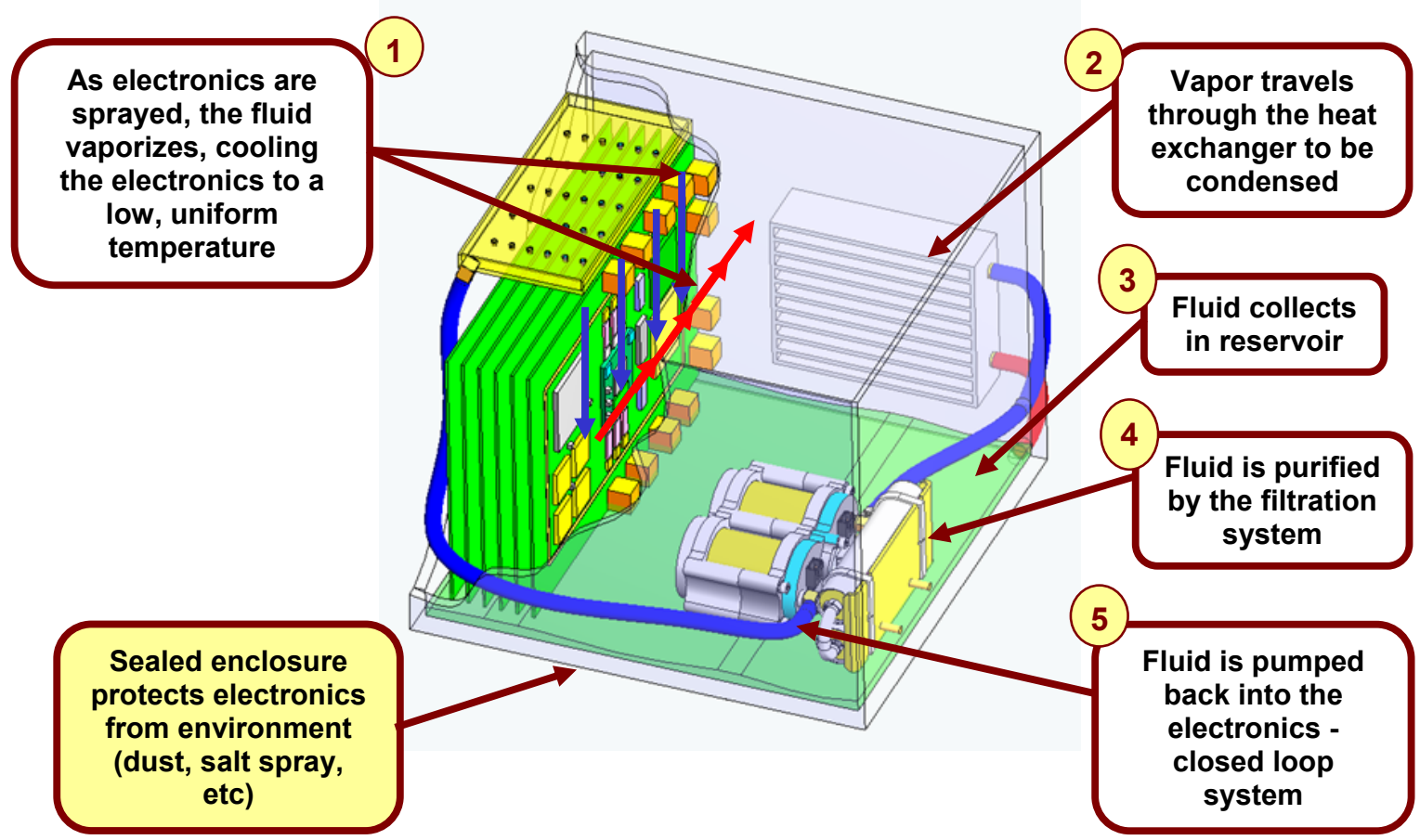




\section{INTERIM REPORT}

\section{ORNL SprayCool Program}

- Program Thermal Management Objectives

Apply SprayCool ${ }^{\mathrm{TM}}$ to a COT AIPM

Design and Build a Laboratory Demonstration System

Characterize DC Conduction Losses

Characterize Dynamometer Testing Performance

- Performance Targets

$>$ Total Heat Acquisition $=3.3 \mathrm{~kW}$

Assume Nominal distribution, $65 \%$ IGBT and $35 \%$ Diode

Each IGBT $=74 \mathrm{~W} / \mathrm{cm}^{2}$ and Each Diode $=80 \mathrm{~W} / \mathrm{cm}^{2}$

$>$ Maintain Junction Temperatures $\leq 125$ Degrees Celsius

- TM System Performance

$>$ Dielectric Fluid Temperature $\leq 105$ Degrees Celsius

Chamber Pressure $<20$ psia

\section{ORNL SprayCool Program FEA}

Analysis Assumptions:

- Heat is uniformly generated in the die

- Cooling fluid is dissipated to $85^{\circ} \mathrm{C}$ oil

-Cooling fluid bulk temp = $100^{\circ} \mathrm{C}$

-Cooling fluid heat transfer coefficients:

$\bullet \mathrm{h}=2 \mathrm{~W} / \mathrm{cm}^{2} \cdot{ }^{\circ} \mathrm{C}$

Spraycool coefficient

$\bullet \mathrm{h}=.2 \mathrm{~W} / \mathrm{cm}^{2} \cdot{ }^{\circ} \mathrm{C}$

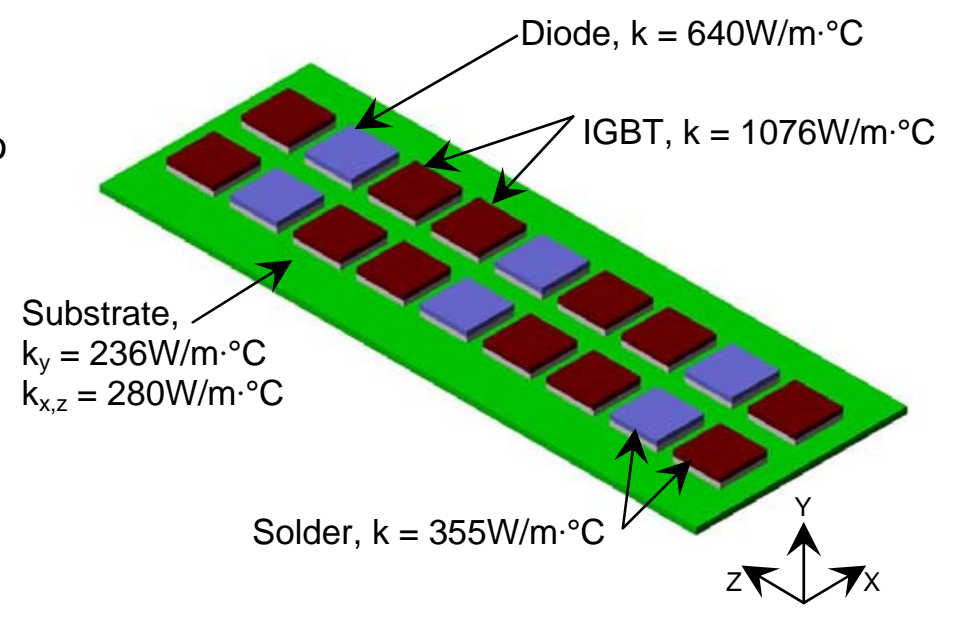

overspray coefficient 


\section{INTERIM REPORT}

\section{ORNL SprayCool Program FEA}

410 A dc, Spray both sides of board

Max Temperature $=118^{\circ} \mathrm{C}$

Heat Loads:

IGBT $=72 \mathrm{~W}$ each $(\mathrm{Qty}=6)$

Diode $=100 \mathrm{~W}$ each $($ Qty $=3)$

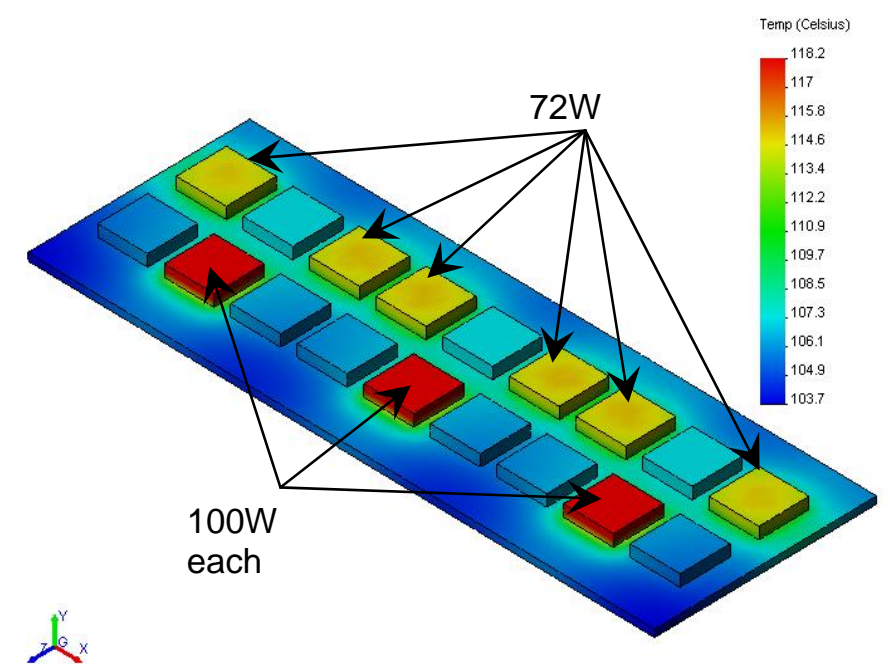

ORNL SprayCool Program Modeling

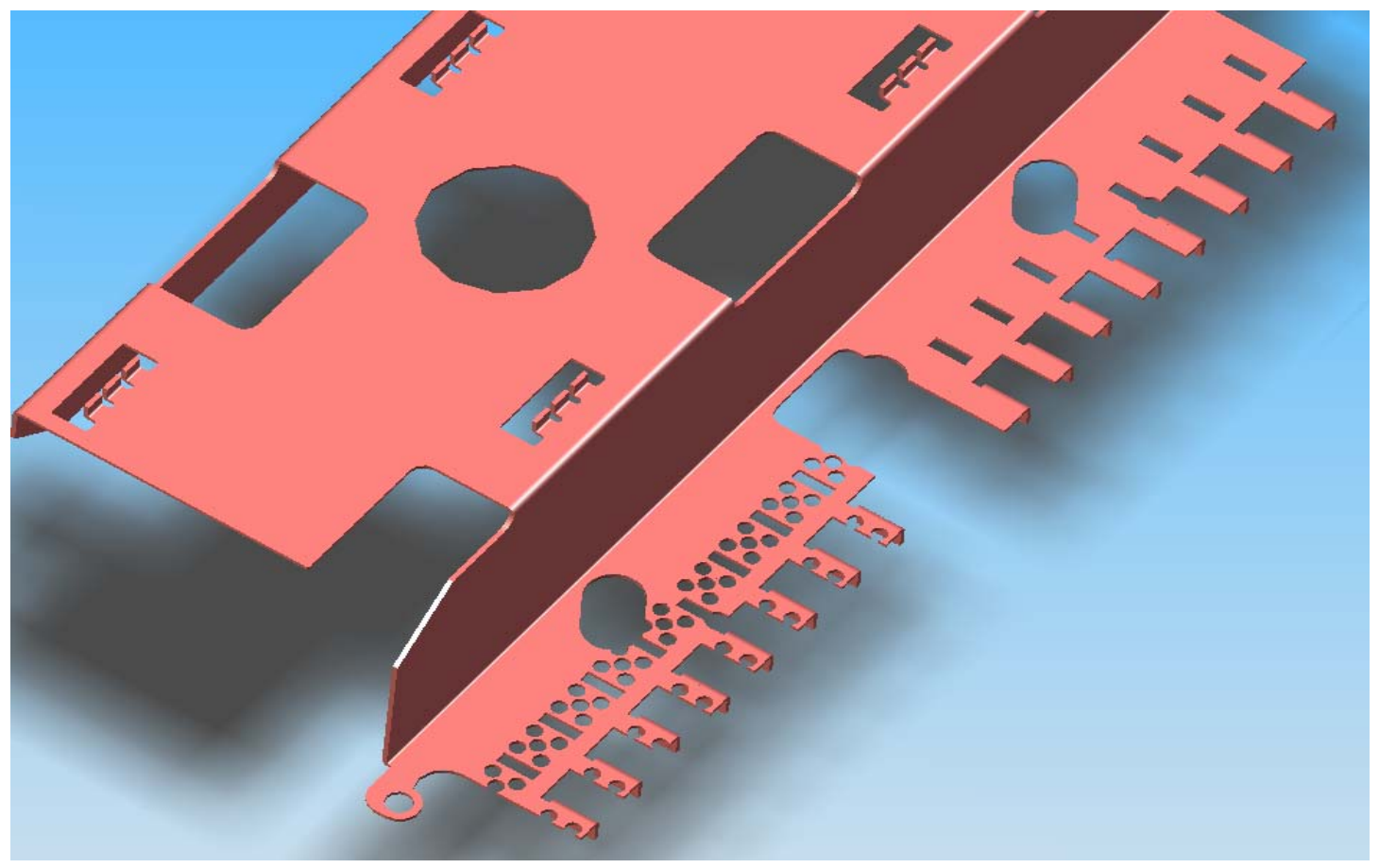




\section{INTERIM REPORT}

\section{ORNL SprayCool Program System}

- Spray Modules

$>$ Two Modules, One on Top, One on Bottom

$>$ One Atomizer Per Die, 108 Total

- Fluid System

$>7$ liters $/$ min @ 30 psid

Pump Power Requirements $\sim 155 \mathrm{~W}$

- Heat Exchanger

$>$ Need 3.5 kW Heat Rejection

$>$ Begin Analysis after Finalizing Module Design

\section{ORNL SprayCool Program Laboratory Unit}

- Design Closed Loop Laboratory Spray Cooling System

$>$ Enclosure

$>$ I/O Electrical/Fluid Interface

$>$ Pump

$>$ Liquid to Liquid Heat Exchanger

- Progress

$>$ Enclosure Design 90\% Complete

$>$ Interface Components Selected

> Pump will be Selected Based on Final Spray Configuration

Heat Exchanger will be Sized Based on Final Spray Configuration 


\section{INTERIM REPORT}

\section{ORNL SprayCool Program Modeling}

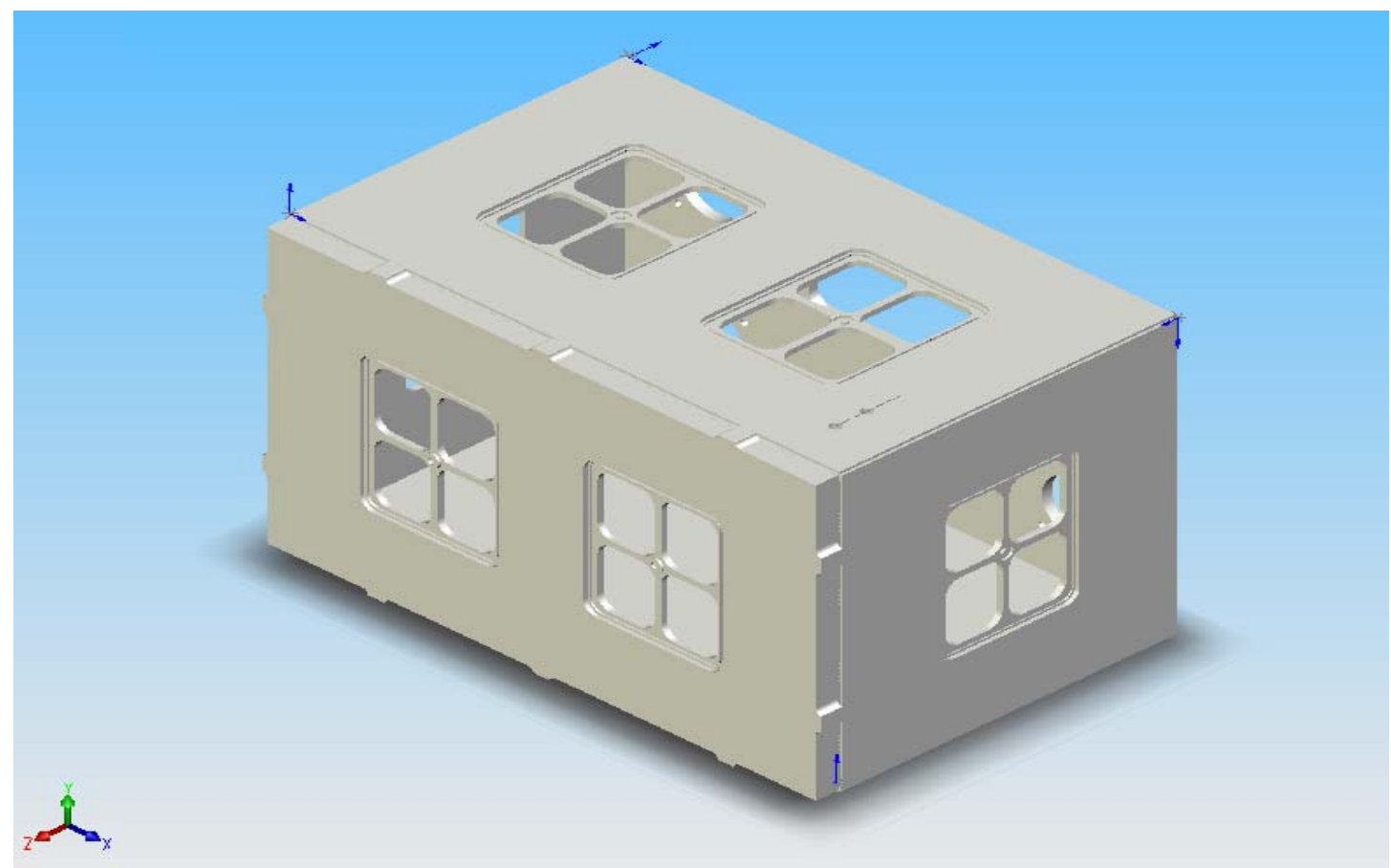

\section{ORNL SprayCool Program Schedule}

- FEA

$>$ Complete Analysis June $3^{\text {rd }}, 2004$

$>$ Review with ORNL

- Spray Modules

$>$ Complete Manufacturing June $25^{\text {th }}, 2004$

$>$ Ship Modules to ORNL for Integration June $30^{\text {th }}, 2004$

- Laboratory Unit

$>$ Complete Manufacturing June $18^{\text {th }}, 2004$

$>$ Test Unit week of June $22^{\text {nd }}, 2004$

- Integration and Test 


\section{INTERIM REPORT}

\section{DISTRIBUTION}

Internal

\author{
1. D. J. Adams \\ 2. E. C. Fox \\ 3. K. P. Gambrell \\ 4. J. S. Hsu
}

\author{
5. L. D. Marlino \\ 6. M. Olszewski \\ 7-8. Laboratory Records
}

\section{External}

9. T. Q. Duong, U.S. Department of Energy, EE-2G/Forrestal Building, 1000 Independence Avenue, S.W., Washington, D.C. 20585.

10. R. R. Fessler, BIZTEK Consulting, Inc., 820 Roslyn Place, Evanston, Illinois 60201-1724.

11. K. Fiegenschuh, Ford Motor Company, Scientific Research Laboratory, 2101 Village Road, MD-2247, Dearborn, Michigan 48121.

12. V. Garg, Ford Motor Company, 15050 Commerce Drive, North, Dearborn, Michigan 48120-1261.

13. E. Jih, Ford Motor Company, Scientific Research Laboratory, 2101 Village Road, MD1170, Rm. 2331, Dearborn, Michigan 48121.

14. W. C. Johnson, University of Tennessee-Knoxville, ECE Department, 414 Ferris Hall, 1508 Middle Drive, Knoxville, Tennessee 37996.

15. A. Lee, Daimler Chrysler, CIMS 484-08-06, 800 Chrysler Drive, Auburn Hills, Michigan 48326-2757.

16. F. Liang, Ford Motor Company, Scientific Research Laboratory, 2101 Village Road, MD1170, Rm. 2331/SRL, Dearborn, Michigan 48121.

17. M. W. Lloyd, Energetics, Inc., 7164 Columbia Gateway Drive, Columbia, Maryland 21046.

18. Brenda Medellon, USCAR, brenda@uscar.org

19. M. Mehall, Ford Motor Company, Scientific Research Laboratory, 2101 Village Road, MD-2247, Rm. 3317, Dearborn, Michigan 48124-2053.

20. J. Rogers, Chemical and Environmental Sciences Laboratory, GM R\&D Center, 30500 Mound Road, Warren, Michigan 48090-9055.

21. S. A. Rogers, U.S. Department of Energy, EE-2G/Forrestal Building, 1000 Independence Avenue, S.W., Washington, D.C. 20585.

22. G. S. Smith, General Motors Advanced Technology Center, 3050 Lomita Boulevard, Torrance, California 90505.

23. E. J. Wall, U.S. Department of Energy, EE-2G/Forrestal Building, 1000 Independence Avenue, S.W., Washington, D.C. 20585.

24. B. Welchko, General Motors Advanced Technology Center, 3050 Lomita Boulevard, Torrance, California 90505.

25. P. G. Yoshida, U.S. Department of Energy, EE-2G/Forrestal Building, 1000 Independence Avenue, S.W., Washington, D.C. 20585. 